\title{
African Plant-Based Natural Products with Antivirulence Activities to the Rescue of Antibiotics
}

\author{
Christian Emmanuel Mahavy ${ }^{1,2}$, Pierre Duez ${ }^{3}{ }^{\mathbb{C}}$, Mondher ElJaziri ${ }^{2}{ }^{\mathbb{D}}$ and \\ Tsiry Rasamiravaka ${ }^{1, *}$ \\ 1 Laboratory of Biotechnology and Microbiology, University of Antananarivo, \\ BP 906 Antananarivo 101, Madagascar; mitsinjomahavy@gmail.com \\ 2 Laboratory of Plant Biotechnology, Université Libre de Bruxelles, B-1050 Brussels, Belgium; jaziri@ulb.ac.be \\ 3 Unit of Therapeutic Chemistry and Pharmacognosy, University of Mons, 7000 Mons, Belgium; \\ pierre.duez@umons.ac.be \\ * Correspondence: travaka@yahoo.fr; Tel.: +261-32-61-903-38
}

Received: 1 November 2020; Accepted: 16 November 2020; Published: 19 November 2020

check for updates

\begin{abstract}
The worldwide emergence of antibiotic-resistant bacteria and the thread of widespread superbug infections have led researchers to constantly look for novel effective antimicrobial agents. Within the past two decades, there has been an increase in studies attempting to discover molecules with innovative properties against pathogenic bacteria, notably by disrupting mechanisms of bacterial virulence and/or biofilm formation which are both regulated by the cell-to-cell communication mechanism called 'quorum sensing' (QS). Certainly, targeting the virulence of bacteria and their capacity to form biofilms, without affecting their viability, may contribute to reduce their pathogenicity, allowing sufficient time for an immune response to infection and a reduction in the use of antibiotics. African plants, through their huge biodiversity, present a considerable reservoir of secondary metabolites with a very broad spectrum of biological activities, a potential source of natural products targeting such non-microbicidal mechanisms. The present paper aims to provide an overview on two main aspects: (i) succinct presentation of bacterial virulence and biofilm formation as well as their entanglement through QS mechanisms and (ii) detailed reports on African plant extracts and isolated compounds with antivirulence properties against particular pathogenic bacteria.
\end{abstract}

Keywords: antivirulence; African plants; biofilm; Escherichia; natural compounds; Pseudomonas; quorum sensing; Ralstonia; Staphylococcus

\section{Introduction}

Antimicrobial resistance, increasingly observed within a wide range of pathogenic bacteria, has become a worldwide threat to public health $[1,2]$. Over time, bacteria adapt to the drugs that are designed to kill them, evolving or selecting resistance mechanisms to ensure survival. The resistance of bacteria to antibiotics is a naturally occurring phenomenon, supposedly progressive over contact with antibiotics. However, the misuse and abuse of antibiotics led to a strong and rapid selective pressure, leading to an uncontrolled widespread development of antibiotic-resistant bacteria $[3,4]$. Beyond resistance to antibiotics, the ability of bacteria to develop effective biofilms represents one of the major obstacles in the fight against bacterial infections. Indeed, while planktonic lifestyle allows bacteria to easily diffuse in diverse environments, their biofilm lifestyle allows efficient colonization of biotic and abiotic surfaces and protection from environmental aggression [5].

Undoubtedly, whenever new antimicrobial compounds would be discovered, their use will result in selective pressures, probably leading targeted bacteria to develop a resistance to these agents. This likely outcome stirs researchers to consider other strategies, notably based on the search for 
original compounds that impair virulence expression mechanisms and/or biofilm formation without affecting bacterial viability [6,7]. Striking such targets will likely impact invasion capabilities and aggressiveness of bacteria, as well as their ability to build protective barriers against host immune defenses or antibiotics; all the while, selective pressure would be minimized [8], most probably preventing or slowing down the apparition and spread of resistances.

The expression of bacterial virulence factors is generally coordinated by quorum sensing (QS) mechanisms, a cell-to-cell communication system that allows bacteria to detect their population density by producing and perceiving diffusible signal molecules that synchronize common behaviors [6]. Depending on bacteria species, QS regulates the production of virulence factors, motilities, and/or biofilm formation. Thus, the disruption of QS signaling, also termed quorum quenching (QQ), appears as interesting adjuvant strategies in the fight against bacterial infections [9].

Over millions of years of co-evolution, plants accumulated highly diverse secondary metabolites (so-called 'natural products'), developing means of surviving in hostile environments that combine herbivorous insects and pathogenic bacteria, fungi, and viruses [10]. Given the huge diversity of flora and ecosystems in the world, the plants likely represent significant sources of innovative compounds with antivirulence properties. Indeed, several studies have already reported natural compounds, mainly isolated from plants, and synthetic compounds interfering with bacterial virulence $[5,11]$. For instance, ajoene, an allyl sulfide isolated from garlic (Allium sativum L., Liliaceae) and baicalin, a flavone glycoside isolated from Huangqin (Scutellaria baicalensis Georgi, Lamiaceae) have been reported to inhibit both virulence factors production and biofilm formation in P. aeruginosa through QQ pathways [12,13].

From an estimated African biodiversity of $\sim 45,000$ plant species, only 5000 have documented medicinal use [14]. The list of drugs provided by the African flora appears quite short (less than 100 active compounds) [15] compared with those from other traditional medical systems such as Traditional Chinese Medicine (more than 2000 active compounds from Chinese herbal) [16], suggesting an unrivalled opportunity for the discovery of new drugs. The present review aims to report on African plants raw extracts and isolated natural compounds with antivirulence properties against particular pathogenic bacteria. As a prerequisite, and to better document these potential antivirulence activities, the first sections of this paper provide an overview of bacterial virulence mechanisms, biofilm formation processes, and their regulation via QS mechanisms. The possible contribution of such antivirulence agents for an efficient control of infective bacteria is also discussed. The literature has been collected from electronic databases such as PubMed, Scopus, and ScienceDirect until August 2020, using relevant keywords including "african medicinal plants, extracts, natural products, virulence, quorum quenching, quorum sensing, biofilm", and their combination.

\section{Bacterial Virulence}

Infections by bacteria are mainly related to their ability to invade and disseminate through their hosts by using different types of motility, by releasing a myriad of virulence factors, by building structured biofilm which lead to host cell and tissue damages, but also to evade immune defense systems $[17,18]$. The present section will briefly discuss these bacterial virulence and invasion processes, schematically summarized in Figure 1. 


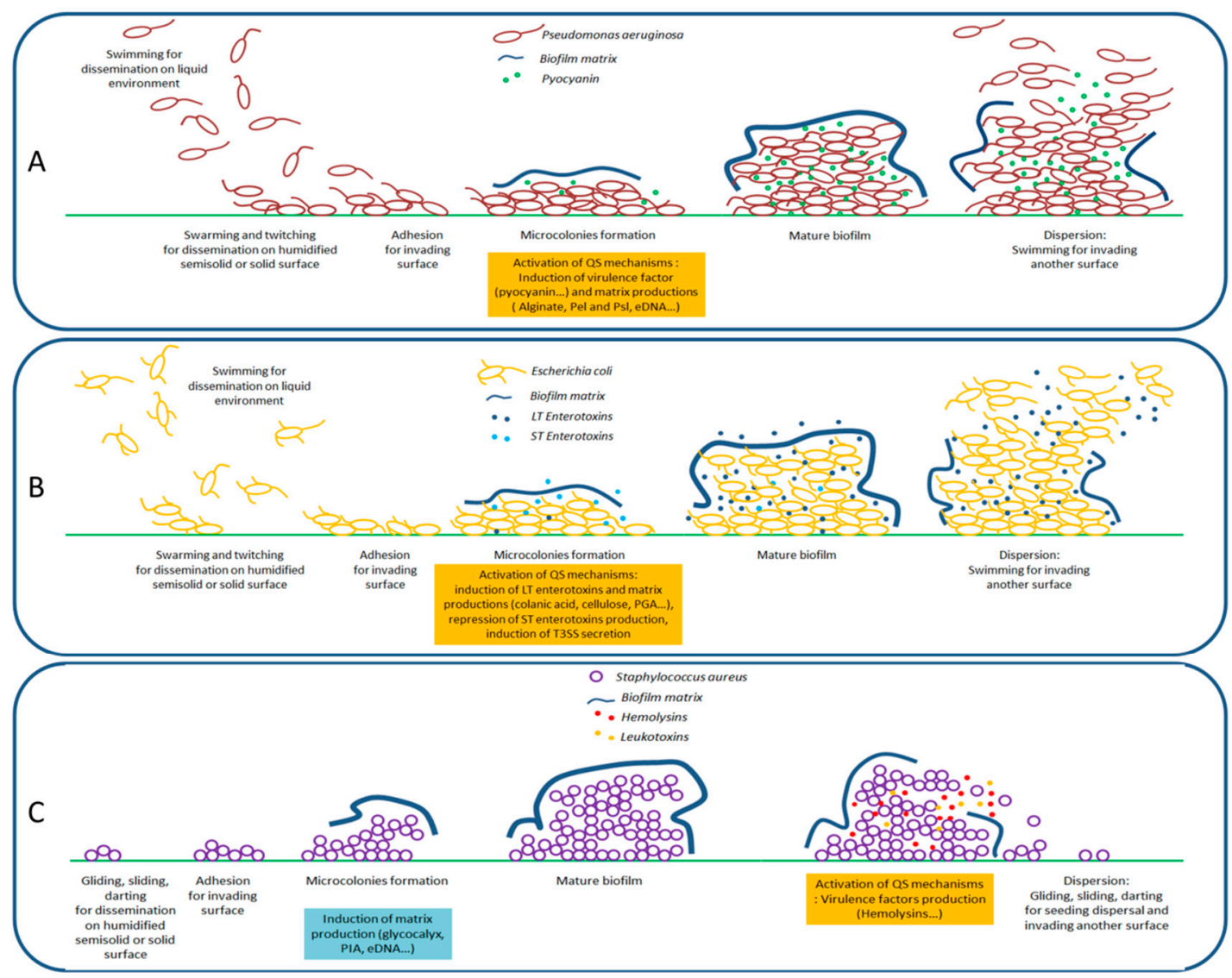

Figure 1. Schematic representation of bacterial invasion processes (A) P. aeruginosa, (B) E. coli, and (C) S. aureus. Bacterial dissemination is done thanks to active and/or passive motilities (swimming, swarming, twitching, gliding, sliding, and darting). In presence of appropriate surfaces and environment, the invasion is initiated by adhesion steps and microcolony formation which lead to the development of mature biofilms in four major steps (adhesion, microcolonies development, biofilm maturation, and dispersion). Under modulation by QS, the bacterial community deploys an arsenal of virulence factors (pyocyanin, heat labile (LT) and heat stable (ST)-enterotoxin, hemolysins, and leukotoxins) that undermine nearby cells (including immune defense cells) and stimulate the production of exogenous biofilm matrix for protection purposes.

\subsection{Motilities and Virulence Factors Production}

Motilities allow bacteria to progress through different surfaces and/or tissues and different forms of motilities can be adopted, depending on bacterial species. Briefly, four active motilities have been reported: swimming, swarming, and twitching, that rely on the presence of flagella and/or type IV pili, and gliding that requires a slime production [19]. For instance, the monotrichous-flagellated P. aeruginosa (Figure 1A) and peritrichous-flagellated E. coli (Figure 1B) have been reported to swim, swarm, and twitch whereas the non-flagellated S. aureus (Figure 1C) is able of gliding by the production of slime guns. Additionally, two passive surface translocations, called sliding and darting, have been evoked, particularly for bacteria that lack the required flagella and type IV pili such as S. aureus [17]. All these motilities allow invasive bacteria to reach appropriate tissues, depending on their tropisms. Once bacteria recognize the host cell receptors or nutrient-rich surroundings, they will colonize the cell surface and release virulence factors.

The ability of bacteria to produce diffusible as well as non-diffusible virulence factors is important in the development and perpetuation of infection [20]. Diffusible virulence factors include enzymes, toxins, pigments, and surfactants that allow bacteria to cause damage to host cells and despoil their nutrient. Non-diffusible ('membrane-associated') virulence factors-including flagella, pili, 
and capsule lipopolysacharrides and lipoproteins-allow bacteria to adhere to their host tissues but also to counteract and evade immune responses. Particularly, the encapsulation of bacteria inhibits the capacity of macrophages and neutrophils to phagocyte them [21]. Moreover, the production of virulence factors lead to severe host damage, well beyond colonized regions; this is particularly the case of exotoxins that can severely dysregulate critical cellular processes. For instance, (i) enterotoxins produced by enterotoxigenic E. coli (ETEC) are a subset of exotoxins that specifically affect the digestive tract and generally result in infectious diarrhea [22]; (ii) the redox properties of pyocyanins permit P. aeruginosa to kill competing microbes as well as mammalian cells and to weaken the immune system of infected lungs during cystic fibrosis [23]; (iii) hemolysins and leukotoxins produced by S. aureus lyse red and white blood cells, including neutrophils, monocytes, granulocytes, and macrophages which severely undermines innate immune defenses [24].

\subsection{Formation of Biofilms}

The biofilm lifestyle is a bacterial behavior in which organized communities of bacteria are encased in an adhesive and protective matrix of extracellular polymeric substances that hold microbial cells together to a surface; the bacterial biofilms allow colonization and persistence over host surfaces as well as evasion from immune cells phagocytosis. Although the biofilm is not a prerequisite for persistent infection [25], it represents a virulence phenotype significantly protecting bacteria from environmental aggressions.

The biofilm formation is relatively similar from one bacteria species to another, a sequence summarized in four major steps: adhesion, microcolonies development, biofilm maturation, and dispersion [26-28]. The extracellular matrix production, initiated at microcolonies development and continued all along the maturation of biofilm, has an adhesin function, allowing bacterial communities to form a rigid and stable structure (Figure 1). These extracellular matrixes are complex environments, essentially composed of water $(97 \%)$, proteins, nucleic acids, lipids/phospholipids, and exopolysaccharide polymers (EPS), differing according to bacterial species/phenotypes. For instance, (i) E. coli produces an EPS mainly represented by cellulose, colanic acid (polymer of glucose, galactose, fucose, and glucuronic acid) and $\beta-1,6-N$-acetyl-D-glucosamine polymers (PGA) [27]; (ii) P. aeruginosa produces at least three types of EPS, mainly alginate (L-guluronic and D-mannuronic acids), Pel (glucose-rich matrix material), and Psl (repeating pentasaccharide units, consisting of D-mannose, L-rhamnose, and D-glucose) that are required for biofilm formation and architecture [29]; and (iii) $S$. aureus mainly produces a glycocalyx primarily composed of teichoic acids and PGA-based exopolysaccharides called "Polysaccharide Intercellular Antigen" (PIA) composed of $\beta-1,6$-linked $\mathrm{N}$-acetylglucosamine residues and a lower content of non- $\mathrm{N}$-acetylated D-glucosaminyl residues that contain phosphate and ester-linked succinate [26].

Interestingly, EPS have been shown to play a major role in the protection properties of biofilm matrix; this is particularly the case for P. aeruginosa, in which both components drastically reduce antimicrobials and microbicide penetration, severely reducing the levels of antibiotics in contact with bacterial cells. The formation of biofilm can then be considered as a real mechanism of bacterial resistance to antibiotics [30]. Moreover, the biofilm lifestyle allows the generation of bacterial persister cells, a specific sub-population of bacterial cells that have acquired temporary antibiotic-resistance phenotypes and for which a long-retention effect, or 'memory effect', has been demonstrated, even if they return at planktonic lifestyle mode [31].

\section{Quorum Sensing and Its Entanglement with the Expression of Virulence}

QS is a cell-to-cell communication used by many bacteria to coordinate common behaviors and regulate a diverse array of physiological activities through the sensing of cell-population densities. In this process, bacteria produce, release, and detect chemical signal molecules called 'autoinducers' (AI) that increase in concentration concomitantly with cell density [32-34]. The reach of a minimal threshold stimulatory concentration leads to activation or induction of QS-dependent gene expression 
among a responding bacterial population. Depending on bacteria species, these processes may include symbiosis, virulence, competence, conjugation, antibiotic production, motility, sporulation, and/or biofilm formation [35]. Basically, there are different types of QS systems based on the nature of $\mathrm{AI}$ and their detection mechanism. The best known and/or relevant systems are (i) the LuxI/R signaling systems, primarily exploited by different Gram-negative bacteria such as Chromobacterium violaceum, Agrobacterium tumefasciens, and P. aeruginosa, based on $N$-acyl homoserine lactones signal molecules (AHLs; also called autoinducer-1, AI-1) and known to promote the production of virulence factors (e.g., violacein, pyocyanin, elastases, and proteases), swarming/twitching motilities, biofilm formation, and other process such as transfer of tumor-inducing plasmid to host [18,36,37]; (ii) the oligopeptide-two-component-type QS system, primarily exploited by Gram-positive bacteria such as Bacillus cereus, Listeria monocytogenes, Streptococcus mutans, Enterococcus faecalis, and S. aureus, based on autoinducing peptides (AIP) as signal molecules and known to up-regulate the expression of several exoproteins genes (e.g., enterotoxins, listeriolysin $\mathrm{O}_{,} \alpha_{-}, \beta-$, and $\gamma$-hemolysins, as well as leucotoxins) and repress the transcription of particular genes encoding for cell wall-associated proteins (e.g., protein A, coagulase, and fibronectin binding protein) [18,38,39]; (iii) the LuxS/AI-2 signaling system, based on (2R, 4S)-2-methyl-2,3,3,4-tetrahydroxytetrahydrofuran (Autoinducer-2, AI-2), exploited by Salmonella spp. and E. coli for interspecies communication, and reported to regulate the expression of over 400 genes associated to bacterial adhesion processes, motilities, and toxin production; (iv) the autoinducer-3/epinephrine/norepinephrine (AI-3/E/NE) signaling system based both on pyrazinones (AI-3), primarily exploited by E. coli for interkingdom communications [40], and on eukaryotic hormones epinephrine/norepinephrine that are reported to activate a virulence-associated type III secretion system (T3SS), causing characteristic histopathologic 'attaching and effacing' lesions on host cells (enterocytes), leading to loss of microvilli and intimate attachment of the bacterium to the host cell surface [41]; and (v) the PhcBSR QS system, based on fatty acids (R)-methyl 3-hydroxymyristate (3-OH MAME) or (R)-methyl 3-hydroxypalmitate (3-OH PAME), employed by Ralstonia solanacearum to regulate virulence factors, EPS, and endoglucanase production [42].

For a better understanding, the QS circuitries of the well-studied systems of human pathogen bacteria (P. aeruginosa, S. aureus, and E. coli) and phytopathogen R. solanacearum are succinctly developed in the supplementary materials (Text S1). Overall, the tight modulation of QS systems controlling the production of virulence factor and the attachment process/biofilm formation is a key component of invasion process and bacterial infection success (Figure 1).

\section{African Plant Extracts with Antivirulence Activities}

This section exposes studies reporting African medicinal plants extracts with antivirulence activities. These extracts, that exert their activities against different models of bacteria, are summarized in Table 1. 
Table 1. African medicinal plant extracts with antivirulence activities

\begin{tabular}{|c|c|c|c|c|c|c|c|c|c|c|c|c|}
\hline \multirow{2}{*}{\multicolumn{2}{|c|}{ Bacterial Model Strains }} & \multirow[b]{2}{*}{ Plant Family $^{1}$} & \multirow[b]{2}{*}{ Plant Species $^{1}$} & \multirow[b]{2}{*}{$\begin{array}{l}\text { Plant Part and } \\
\text { Traditional } \\
\text { Usage }\end{array}$} & \multirow[b]{2}{*}{$\begin{array}{c}\text { Active } \\
\text { Extracts } \\
\text { (or Fraction) }\end{array}$} & \multirow[b]{2}{*}{$\begin{array}{c}\text { Bactericidal } \\
\text { Effect MIC } \\
(\mu \mathrm{g} / \mathrm{mL})\end{array}$} & \multicolumn{4}{|c|}{ Impact on Bacterial Virulence $^{2}$} & \multirow[b]{2}{*}{$\begin{array}{l}\text { Synergy } \\
\text { with } \\
\text { Antibiotics }\end{array}$} & \multirow[b]{2}{*}{ References } \\
\hline & & & & & & & Motility & $\begin{array}{l}\text { Virulence } \\
\text { Factors } \\
\text { Production }\end{array}$ & $\begin{array}{l}\text { Biofilm } \\
\text { Formation }\end{array}$ & QS & & \\
\hline \multirow{9}{*}{ 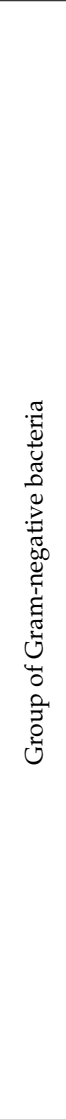 } & A. tumefaciens & Bignoniaceae & $\begin{array}{l}\text { Kigelia africana } \\
\text { (Lam.) Benth }\end{array}$ & $\begin{array}{c}\text { Fruit; dysentery, } \\
\text { toothaches, } \\
\text { malaria, } \\
\text { diabetes }\end{array}$ & Hexane & NC & NC & $\searrow$ & NC & $\searrow$ & NC & [43] \\
\hline & C. violaceum & Asteraceae & $\begin{array}{l}\text { Baccharoides } \\
\text { adoensis } \\
\text { (Sch. Bip. } \\
\text { ex Walp.) H. } \\
\text { Rob. [synonym } \\
\text { of Vernonia } \\
\text { adoensis Schi.Bip. } \\
\text { ex Walp.] }\end{array}$ & $\begin{array}{l}\text { Bark; urinary } \\
\text { tract infections }\end{array}$ & $\begin{array}{l}\text { Distilled } \\
\text { water }\end{array}$ & 4000 & $\mathrm{NC}$ & $\leftrightarrow$ & $\searrow$ & $\mathrm{NC}$ & $\mathrm{NC}$ & [44] \\
\hline & \multirow{7}{*}{$\begin{array}{l}\text { C. violaceum } \\
\text { ATCC } 12472\end{array}$} & Aristolochiaceae & $\begin{array}{l}\text { Hydnora africana } \\
\text { Thumb. }\end{array}$ & $\begin{array}{l}\text { Bark; urinary } \\
\text { tract infections }\end{array}$ & Methanol & 1000 & \multirow[t]{2}{*}{$\mathrm{NC}$} & \multirow[t]{2}{*}{$\searrow$} & \multirow[t]{2}{*}{$\searrow$} & \multirow[t]{2}{*}{ NC } & \multirow[t]{2}{*}{ NC } & \multirow[t]{2}{*}{ [44] } \\
\hline & & Aspagaceae & $\begin{array}{l}\text { Eucomis } \\
\text { autumnalis } \\
\text { (Mill.) Chitt }\end{array}$ & $\begin{array}{l}\text { Bulb; urinary } \\
\text { tract infections }\end{array}$ & Methanol & $2000-4000$ & & & & & & \\
\hline & & Bignoniaceae & $\begin{array}{l}\text { Kigelia africana } \\
\text { (Lam.) Benth }\end{array}$ & $\begin{array}{c}\text { Fruit; dysentery, } \\
\text { toothaches, } \\
\text { malaria, } \\
\text { diabetes }\end{array}$ & Hexane & $\mathrm{NC}$ & $\mathrm{NC}$ & $\searrow$ & $\mathrm{NC}$ & $\searrow$ & $\mathrm{NC}$ & [43] \\
\hline & & Hypoxidaceae & $\begin{array}{c}\text { Hypoxis } \\
\text { hemerocallidea } \\
\text { Fish., C.A.Mey. } \\
\text { \& Avé-Lall. }\end{array}$ & $\begin{array}{l}\text { Corm; urinary } \\
\text { tract infections }\end{array}$ & Dichloromethane & 2000 & \multirow{4}{*}{ NC } & \multirow{4}{*}{$\searrow$} & $\searrow$ & \multirow{4}{*}{$\mathrm{NC}$} & \multirow{4}{*}{$\mathrm{NC}$} & \multirow{4}{*}{ [44] } \\
\hline & & Lauraceae & $\begin{array}{l}\text { Cryptocarya } \\
\text { latifolia Sond. }\end{array}$ & $\begin{array}{l}\text { Bark; urinary } \\
\text { tract infections }\end{array}$ & Methanol & \multirow{3}{*}{$2000-4000$} & & & $\leftrightarrow$ & & & \\
\hline & & Poacae & $\begin{array}{l}\text { Cenchrus ciliaris } \\
\text { L. }\end{array}$ & $\begin{array}{l}\text { Leaves; urinary } \\
\text { tract infections }\end{array}$ & Methanol & & & & $\searrow$ & & & \\
\hline & & Vitaceae & $\begin{array}{c}\text { Rhoicissus } \\
\text { tridentata (L.f.) } \\
\text { Wild \& } \\
\text { R.B.Drumm }\end{array}$ & $\begin{array}{l}\text { Roots; urinary } \\
\text { tract infections }\end{array}$ & Methanol & & & & $\leftrightarrow$ & & & \\
\hline
\end{tabular}


Table 1. Cont.

\begin{tabular}{|c|c|c|c|c|c|c|c|c|c|c|c|}
\hline \multirow[b]{2}{*}{ Bacterial Model Strains } & \multirow[b]{2}{*}{ Plant Family $^{1}$} & \multirow[b]{2}{*}{ Plant Species $^{1}$} & \multirow[b]{2}{*}{$\begin{array}{l}\text { Plant Part and } \\
\text { Traditional } \\
\text { Usage }\end{array}$} & \multirow[b]{2}{*}{$\begin{array}{c}\text { Active } \\
\text { Extracts } \\
\text { (or Fraction) }\end{array}$} & \multirow[b]{2}{*}{$\begin{array}{c}\text { Bactericidal } \\
\text { Effect MIC } \\
(\mu \mathrm{g} / \mathrm{mL})\end{array}$} & \multicolumn{4}{|c|}{ Impact on Bacterial Virulence $^{2}$} & \multirow[b]{2}{*}{$\begin{array}{l}\text { Synergy } \\
\text { with } \\
\text { Antibiotics }\end{array}$} & \multirow[b]{2}{*}{ References } \\
\hline & & & & & & Motility & $\begin{array}{l}\text { Virulence } \\
\text { Factors } \\
\text { Production }\end{array}$ & $\begin{array}{l}\text { Biofilm } \\
\text { Formation }\end{array}$ & QS & & \\
\hline \multirow{5}{*}{$\begin{array}{l}\text { C. violaceum } \\
\text { CV026 }\end{array}$} & \multirow[t]{2}{*}{ Combretaceae } & $\begin{array}{c}\text { Terminalia } \\
\text { leiocarpa (DC.) } \\
\text { Baill. [synonym } \\
\text { of Anogeissus } \\
\text { leiocarpus (DC) } \\
\text { Guill. et Perr.] }\end{array}$ & $\begin{array}{l}\text { Stem bark; treat } \\
\text { infected burn } \\
\text { wounds }\end{array}$ & Methanol & 1250 & NC & $\searrow$ & $\leftrightarrow$ & $\mathrm{NC}$ & NC & [45] \\
\hline & & $\begin{array}{l}\text { Terminalia } \\
\text { macroptera Guill. } \\
\text { and Perr. }\end{array}$ & $\begin{array}{c}\text { Bark; } \\
\text { respiratory tract } \\
\text { diseases, skin } \\
\text { diseases, and } \\
\text { wound }\end{array}$ & & & NC & $\searrow$ & $\searrow$ & $\searrow$ & NC & [46] \\
\hline & Fabaceae & $\begin{array}{l}\text { Vachellia seyal } \\
\text { (Delile) } \\
\text { P.J.H.Hurter } \\
\text { [synonym of } \\
\text { Acacia seyal } \\
\text { Delile] }\end{array}$ & $\begin{array}{l}\text { Bark; toothache, } \\
\text { dysentery, burns }\end{array}$ & Methanol & NC & NC & $\searrow$ & NC & $\mathrm{NC}$ & NC & [47] \\
\hline & Mimosaceae & $\begin{array}{l}\text { Acacia dudgeoni } \\
\text { Craib. ex } \\
\text { Holland }\end{array}$ & $\begin{array}{l}\text { Bark; diarrhea, } \\
\text { childhood } \\
\text { dysentery }\end{array}$ & Methanol & NC & NC & $\searrow$ & NC & $\searrow$ & NC & [48] \\
\hline & Zygophyllaceae & $\begin{array}{c}\text { Balanites } \\
\text { aegyptiaca (L.) } \\
\text { Delille. }\end{array}$ & $\begin{array}{l}\text { Galls and stem } \\
\text { bark; respiratory } \\
\text { tract diseases, } \\
\text { skin diseases } \\
\text { and wound }\end{array}$ & Methanol & 1250 & $\mathrm{NC}$ & $\searrow$ & $\searrow$ & $\leftrightarrow$ & $\mathrm{NC}$ & [46] \\
\hline \multirow[t]{2}{*}{ E. coli } & Acanthaceae & $\begin{array}{c}\text { Justicia } \\
\text { schimperiana } \\
\text { (Hochst. ex } \\
\text { Nees) T. } \\
\text { Anderson }\end{array}$ & $\begin{array}{l}\text { Whole plant; } \\
\text { malaria, cough, } \\
\text { stomach, } \\
\text { asthma }\end{array}$ & $\begin{array}{l}\text { Petroleum } \\
\text { ether }\end{array}$ & NC & NC & NC & NC & $\searrow$ & NC & [49] \\
\hline & Fabaceae & $\begin{array}{l}\text { Albizia } \\
\text { Schimperiana } \\
\text { Oliv. }\end{array}$ & $\begin{array}{c}\text { Leaves; } \\
\text { antifungal }\end{array}$ & Methanol & NC & NC & $\mathrm{NC}$ & NC & $\searrow$ & $\mathrm{NC}$ & [49] \\
\hline
\end{tabular}


Table 1. Cont.

\begin{tabular}{|c|c|c|c|c|c|c|c|c|c|c|c|}
\hline \multirow[b]{2}{*}{ Bacterial Model Strains } & \multirow[b]{2}{*}{ Plant Family ${ }^{1}$} & \multirow[b]{2}{*}{ Plant Species ${ }^{1}$} & \multirow[b]{2}{*}{$\begin{array}{l}\text { Plant Part and } \\
\text { Traditional } \\
\text { Usage }\end{array}$} & \multirow[b]{2}{*}{$\begin{array}{c}\text { Active } \\
\text { Extracts } \\
\text { (or Fraction) }\end{array}$} & \multirow[b]{2}{*}{$\begin{array}{l}\text { Bactericidal } \\
\text { Effect MIC } \\
(\mu \mathrm{g} / \mathrm{mL})\end{array}$} & \multicolumn{4}{|c|}{ Impact on Bacterial Virulence $^{2}$} & \multirow[b]{2}{*}{$\begin{array}{l}\text { Synergy } \\
\text { with } \\
\text { Antibiotics }\end{array}$} & \multirow[b]{2}{*}{ References } \\
\hline & & & & & & Motility & $\begin{array}{l}\text { Virulence } \\
\text { Factors } \\
\text { Production }\end{array}$ & $\begin{array}{l}\text { Biofilm } \\
\text { Formation }\end{array}$ & QS & & \\
\hline \multirow{6}{*}{$\begin{array}{c}\text { E. coli ATCC } \\
25922\end{array}$} & \multirow{6}{*}{ Myrtaceae } & $\begin{array}{l}\text { Eugenia } \\
\text { erythrophylla } \\
\text { Strey }\end{array}$ & \multirow{6}{*}{$\begin{array}{c}\text { Leaves; } \\
\text { diarrhea, } \\
\text { diabetes, } \\
\text { reproductive } \\
\text { problems, } \\
\text { and respiratory } \\
\text { conditions }\end{array}$} & \multirow{6}{*}{ Acetone } & \multirow{6}{*}{$80-310$} & \multirow{6}{*}{$\mathrm{NC}$} & \multirow{6}{*}{$\mathrm{NC}$} & \multirow{6}{*}{$\searrow$} & \multirow{6}{*}{$\mathrm{NC}$} & \multirow{6}{*}{$\mathrm{NC}$} & \multirow{6}{*}{ [50] } \\
\hline & & $\begin{array}{c}\text { Eugenia } \\
\text { umtamvunensis } \\
\text { A.E.van Wyk }\end{array}$ & & & & & & & & & \\
\hline & & $\begin{array}{c}\text { Eugenia capensis } \\
\text { subsp. zeyheri } \\
\text { (Harv.) F.White } \\
\text { [synonym of } \\
\text { Eugenia zeyheri } \\
\text { (Harv.) Harv.] }\end{array}$ & & & & & & & & & \\
\hline & & $\begin{array}{c}\text { Syzygium legatii } \\
\text { Burtt Davy \& } \\
\text { Greenway }\end{array}$ & & & & & & & & & \\
\hline & & $\begin{array}{c}\text { Syzygium } \\
\text { masukuense } \\
\text { (Baker) R.E.Fr. }\end{array}$ & & & & & & & & & \\
\hline & & Syzygium sp. & & & & & & & & & \\
\hline \multirow[b]{2}{*}{$\begin{array}{c}\text { E. coli } \\
\text { pBCA9145-jtk2828: } \\
\text { sfGFP }\end{array}$} & Celastraceae & $\begin{array}{l}\text { Elaeodendron } \\
\text { buchananii } \\
\text { (Loes). Loes. }\end{array}$ & \multirow[b]{2}{*}{$\begin{array}{l}\text { Roots; } \\
\text { gastrointestinal } \\
\text { tract, urinary } \\
\text { tract, skin, } \\
\text { and oral cavity }\end{array}$} & \multirow[b]{2}{*}{ Ethanol } & \multirow[b]{2}{*}{500} & \multirow[b]{2}{*}{$\mathrm{NC}$} & \multirow[b]{2}{*}{$\leftrightarrow$} & \multirow[b]{2}{*}{$\leftrightarrow$} & \multirow[b]{2}{*}{$\searrow$} & \multirow[b]{2}{*}{$\mathrm{NC}$} & \multirow[b]{2}{*}{ [51] } \\
\hline & Fabaceae & $\begin{array}{c}\text { Vachellia } \\
\text { gerrardii (Benth.) } \\
\text { P.J.H.Hurter } \\
\text { [synonym of } \\
\text { Acacia gerrardii } \\
\text { Benth] }\end{array}$ & & & & & & & & & \\
\hline
\end{tabular}


Table 1. Cont.

\begin{tabular}{|c|c|c|c|c|c|c|c|c|c|c|c|}
\hline \multirow[b]{2}{*}{ Bacterial Model Strains } & \multirow[b]{2}{*}{ Plant Family $^{1}$} & \multirow[b]{2}{*}{ Plant Species $^{1}$} & \multirow[b]{2}{*}{$\begin{array}{l}\text { Plant Part and } \\
\text { Traditional } \\
\text { Usage }\end{array}$} & \multirow[b]{2}{*}{$\begin{array}{c}\text { Active } \\
\text { Extracts } \\
\text { (or Fraction) }\end{array}$} & \multirow[b]{2}{*}{$\begin{array}{c}\text { Bactericidal } \\
\text { Effect MIC } \\
(\mu \mathrm{g} / \mathrm{mL})\end{array}$} & \multicolumn{4}{|c|}{ Impact on Bacterial Virulence $^{2}$} & \multirow[b]{2}{*}{$\begin{array}{l}\text { Synergy } \\
\text { with } \\
\text { Antibiotics }\end{array}$} & \multirow[b]{2}{*}{ References } \\
\hline & & & & & & Motility & $\begin{array}{l}\text { Virulence } \\
\text { Factors } \\
\text { Production }\end{array}$ & $\begin{array}{l}\text { Biofilm } \\
\text { Formation }\end{array}$ & QS & & \\
\hline \multirow{4}{*}{$\begin{array}{c}\text { P. aeruginosa ATCC } \\
27853\end{array}$} & \multirow{4}{*}{ Myrtaceae } & $\begin{array}{l}\text { Eugenia } \\
\text { erythrophylla } \\
\text { Strey }\end{array}$ & \multirow{4}{*}{$\begin{array}{l}\text { Leaves; } \\
\text { diarrhea, } \\
\text { diabetes, } \\
\text { reproductive } \\
\text { problems, } \\
\text { and respiratory } \\
\text { conditions }\end{array}$} & \multirow{4}{*}{ Acetone } & \multirow{4}{*}{$80-310$} & \multirow{4}{*}{$\mathrm{NC}$} & \multirow{4}{*}{$\mathrm{NC}$} & \multirow{4}{*}{$\searrow$} & \multirow{4}{*}{$\mathrm{NC}$} & \multirow{4}{*}{$\mathrm{NC}$} & \multirow{4}{*}{ [50] } \\
\hline & & $\begin{array}{c}\text { Eugenia } \\
\text { umtamvunensis } \\
\text { A.E.van Wyk }\end{array}$ & & & & & & & & & \\
\hline & & $\begin{array}{l}\text { Eugenia capensis } \\
\text { subsp. zeyheri } \\
\text { (Harv.) F.White } \\
\text { [synonym of } \\
\text { Eugenia zeyheri } \\
\text { (Harv.) Harv.] }\end{array}$ & & & & & & & & & \\
\hline & & $\begin{array}{l}\text { Syzygium legatii } \\
\text { Burtt Davy \& } \\
\text { Greenway }\end{array}$ & & & & & & & & & \\
\hline $\begin{array}{c}\text { P. aeruginosa ATCC } \\
\quad 35032\end{array}$ & Fabaceae & $\begin{array}{c}\text { Lessertia } \\
\text { frutescens (L.) } \\
\text { Goldblatt \& } \\
\text { J.C.Manning } \\
\text { [synonym of } \\
\text { Sutherlandia } \\
\text { frutescens (L) } \\
\text { R. Br.] }\end{array}$ & $\begin{array}{l}\text { Leaves; cancers, } \\
\text { fever, diabetes }\end{array}$ & Ethanol & $\mathrm{NC}$ & NC & $\searrow$ & $\searrow$ & $\mathrm{NC}$ & $\mathrm{NC}$ & [52] \\
\hline $\begin{array}{l}\text { P. aeruginosa MTCC } \\
2453\end{array}$ & Anacardiaceae & $\begin{array}{l}\text { Sclerocarya birrea } \\
\text { (A.Rich.) Hoch }\end{array}$ & $\begin{array}{l}\text { Stem bark; } \\
\text { dysentery, } \\
\text { diarrhea }\end{array}$ & Methanol & $\mathrm{NC}$ & $\searrow$ & $\searrow$ & $\searrow$ & $\mathrm{NC}$ & $\mathrm{NC}$ & [53] \\
\hline \multirow[t]{2}{*}{ P. aeruginosa PAO1 } & Baroginaceae & $\begin{array}{l}\text { Cordia gilletii De } \\
\text { Wild }\end{array}$ & $\begin{array}{l}\text { Root barks; } \\
\text { malaria, } \\
\text { diarrhea, } \\
\text { wounds, } \\
\text { and skin } \\
\text { diseases }\end{array}$ & Dichloromethane & $\mathrm{NC}$ & $\mathrm{NC}$ & $\searrow$ & $\searrow$ & $\searrow$ & NC & [54] \\
\hline & Buddlejaceae & $\begin{array}{c}\text { Buddleja } \\
\text { madagascariensis } \\
\text { Lam. }\end{array}$ & $\begin{array}{l}\text { Leaves; potato } \\
\text { wilt diseases }\end{array}$ & Methanol & 4000 & NC & NC & $\searrow$ & $\searrow$ & NC & [55] \\
\hline
\end{tabular}


Table 1. Cont.

\begin{tabular}{|c|c|c|c|c|c|c|c|c|c|c|c|}
\hline \multirow[b]{2}{*}{ Bacterial Model Strains } & \multirow[b]{2}{*}{ Plant Family ${ }^{1}$} & \multirow[b]{2}{*}{ Plant Species ${ }^{1}$} & \multirow[b]{2}{*}{$\begin{array}{l}\text { Plant Part and } \\
\text { Traditional } \\
\text { Usage }\end{array}$} & \multirow[b]{2}{*}{$\begin{array}{c}\text { Active } \\
\text { Extracts } \\
\text { (or Fraction) }\end{array}$} & \multirow[b]{2}{*}{$\begin{array}{c}\text { Bactericidal } \\
\text { Effect MIC } \\
(\mu \mathrm{g} / \mathrm{mL})\end{array}$} & \multicolumn{4}{|c|}{ Impact on Bacterial Virulence ${ }^{2}$} & \multirow[b]{2}{*}{$\begin{array}{l}\text { Synergy } \\
\text { with } \\
\text { Antibiotics }\end{array}$} & \multirow[b]{2}{*}{ References } \\
\hline & & & & & & Motility & $\begin{array}{l}\text { Virulence } \\
\text { Factors } \\
\text { Production }\end{array}$ & $\begin{array}{l}\text { Biofilm } \\
\text { Formation }\end{array}$ & QS & & \\
\hline & Combretaceae & $\begin{array}{c}\text { Terminalia } \\
\text { leiocarpa (DC.) } \\
\text { Baill. [synonym } \\
\text { of Anogeissus } \\
\text { leiocarpus (DC) } \\
\text { Guill. et Perr.] }\end{array}$ & $\begin{array}{l}\text { Stem bark; treat } \\
\text { infected burn } \\
\text { wounds }\end{array}$ & Methanol & 1250 & $\mathrm{NC}$ & $\searrow$ & $\leftrightarrow$ & $\mathrm{NC}$ & $\mathrm{NC}$ & [45] \\
\hline & \multirow[t]{3}{*}{ Fabaceae } & $\begin{array}{c}\text { Vachellia seyal } \\
\text { (Delile) } \\
\text { P.J.H.Hurter } \\
\text { [synonym of } \\
\text { Acacia seyal } \\
\text { Delile] }\end{array}$ & $\begin{array}{l}\text { Bark; toothache, } \\
\text { dysentery, burns }\end{array}$ & Methanol & $\mathrm{NC}$ & $\mathrm{NC}$ & $\searrow$ & $\searrow$ & $\mathrm{NC}$ & $\mathrm{NC}$ & [47] \\
\hline & & $\begin{array}{c}\text { Dalbergia } \\
\text { trichocarpa Baker }\end{array}$ & $\begin{array}{l}\text { Bark; laryngitis, } \\
\text { diarrhea }\end{array}$ & $\begin{array}{c}\text { Hexane } \\
\text { (F1 Fraction) }\end{array}$ & 4000 & $\searrow$ & $\searrow$ & $\searrow$ & $\leftrightarrow$ & yes & [56] \\
\hline & & $\begin{array}{c}\text { Tephrosia } \\
\text { purpurea (L.) } \\
\text { Pers. }\end{array}$ & $\begin{array}{l}\text { Leaves; potato } \\
\text { wilt diseases }\end{array}$ & Methanol & 4000 & NC & NC & $\searrow$ & $\leftrightarrow$ & $\mathrm{NC}$ & [55] \\
\hline & Mimosaceae & $\begin{array}{l}\text { Acacia dudgeoni } \\
\text { Craib. ex } \\
\text { Holland }\end{array}$ & $\begin{array}{l}\text { Bark; diarrhea, } \\
\text { childhood } \\
\text { dysentery }\end{array}$ & Methanol & $\mathrm{NC}$ & NC & $\searrow$ & $\searrow$ & $\mathrm{NC}$ & $\mathrm{NC}$ & [48] \\
\hline & Rubiaceae & $\begin{array}{l}\text { Crossopteryx } \\
\text { febrifuga (Afzel } \\
\text { ex G. Don) } \\
\text { Benth }\end{array}$ & $\begin{array}{l}\text { Leaves and } \\
\text { stem; typhoid } \\
\text { fever, } \\
\text { respiratory } \\
\text { infections, } \\
\text { infected } \\
\text { wounds, dental } \\
\text { diseases }\end{array}$ & \multirow[t]{2}{*}{ Methanol } & \multirow[t]{2}{*}{$\mathrm{NC}$} & \multirow[t]{2}{*}{$\mathrm{NC}$} & \multirow[t]{2}{*}{$\searrow$} & \multirow[t]{2}{*}{$\mathrm{NC}$} & \multirow[t]{2}{*}{$\mathrm{NC}$} & \multirow[t]{2}{*}{$\mathrm{NC}$} & \multirow[t]{2}{*}{ [57] } \\
\hline & Rutaceae & $\begin{array}{l}\text { Zanthoxylum } \\
\text { zanthoxyloides } \\
\text { (Lam) Zepern. } \\
\text { and Timler }\end{array}$ & $\begin{array}{l}\text { Stem bark; } \\
\text { typhoid fever, } \\
\text { respiratory } \\
\text { infections, } \\
\text { infected } \\
\text { wounds, dental } \\
\text { diseases }\end{array}$ & & & & & & & & \\
\hline & Zygophyllaceae & $\begin{array}{c}\text { Balanites } \\
\text { aegyptiaca (L.) } \\
\text { Delille }\end{array}$ & $\begin{array}{l}\text { Galls and stem } \\
\text { bark; respiratory } \\
\text { tract diseases, } \\
\text { skin diseases } \\
\text { and wound }\end{array}$ & Methanol & 625 & NC & $\searrow$ & $\searrow$ & $\leftrightarrow$ & $\mathrm{NC}$ & [46] \\
\hline
\end{tabular}


Table 1. Cont.

\begin{tabular}{|c|c|c|c|c|c|c|c|c|c|c|c|}
\hline \multirow[b]{2}{*}{ Bacterial Model Strains } & \multirow[b]{2}{*}{ Plant Family $^{1}$} & \multirow[b]{2}{*}{ Plant Species ${ }^{1}$} & \multirow[b]{2}{*}{$\begin{array}{l}\text { Plant Part and } \\
\text { Traditional } \\
\text { Usage }\end{array}$} & \multirow[b]{2}{*}{$\begin{array}{c}\text { Active } \\
\text { Extracts } \\
\text { (or Fraction) }\end{array}$} & \multirow[b]{2}{*}{$\begin{array}{c}\text { Bactericidal } \\
\text { Effect MIC } \\
(\mu \mathrm{g} / \mathrm{mL})\end{array}$} & \multicolumn{4}{|c|}{ Impact on Bacterial Virulence $^{2}$} & \multirow[b]{2}{*}{$\begin{array}{l}\text { Synergy } \\
\text { with } \\
\text { Antibiotics }\end{array}$} & \multirow[b]{2}{*}{ References } \\
\hline & & & & & & Motility & $\begin{array}{c}\text { Virulence } \\
\text { Factors } \\
\text { Production }\end{array}$ & $\begin{array}{l}\text { Biofilm } \\
\text { Formation }\end{array}$ & QS & & \\
\hline \multirow{2}{*}{ R. solanacearum } & Fabaceae & $\begin{array}{c}\text { Tephrosia } \\
\text { purpurea (L.) } \\
\text { Pers. }\end{array}$ & $\begin{array}{l}\text { Leaves; potato } \\
\text { wilt diseases }\end{array}$ & Methanol & 4000 & NC & $\mathrm{NC}$ & $\searrow$ & $\leftrightarrow$ & $\mathrm{NC}$ & \multirow{2}{*}{ [55] } \\
\hline & Scrophulariaceae & $\begin{array}{c}\text { Buddleja } \\
\text { madagascariensis } \\
\text { Lam }\end{array}$ & $\begin{array}{l}\text { Leaves; potato } \\
\text { wilt diseases }\end{array}$ & Methanol & 4000 & NC & NC & $\searrow$ & $\searrow$ & $\mathrm{NC}$ & \\
\hline \multirow{6}{*}{$\begin{array}{l}\text { Salmonella ser. } \\
\text { Typhimurium } \\
\text { ATCC } 39183\end{array}$} & \multirow{6}{*}{ Myrtaceae } & $\begin{array}{c}\text { Eugenia } \\
\text { erythrophylla } \\
\text { Strey }\end{array}$ & \multirow{6}{*}{$\begin{array}{l}\text { Leaves; } \\
\text { diarrhea, } \\
\text { diabetes, } \\
\text { reproductive } \\
\text { problems, and } \\
\text { respiratory } \\
\text { conditions }\end{array}$} & \multirow{6}{*}{ Acetone } & \multirow{6}{*}{$40-310$} & \multirow{6}{*}{$\mathrm{NC}$} & \multirow{6}{*}{$\mathrm{NC}$} & \multirow{6}{*}{$\searrow$} & \multirow{6}{*}{$\mathrm{NC}$} & \multirow{6}{*}{$\mathrm{NC}$} & \multirow{6}{*}{ [50] } \\
\hline & & $\begin{array}{c}\text { Eugenia } \\
\text { umtamvunensis } \\
\text { A.E.van Wyk }\end{array}$ & & & & & & & & & \\
\hline & & $\begin{array}{c}\text { Eugenia capensis } \\
\text { subsp. zeyheri } \\
\text { (Harv.) F.White } \\
\text { [synonym of } \\
\text { Eugenia zeyheri } \\
\text { (Harv.) Harv.] }\end{array}$ & & & & & & & & & \\
\hline & & $\begin{array}{l}\text { Syzygium legatii } \\
\text { Burtt Davy \& } \\
\text { Greenway }\end{array}$ & & & & & & & & & \\
\hline & & $\begin{array}{c}\text { Syzygium } \\
\text { masukuense } \\
\text { (Baker) R.E.Fr. }\end{array}$ & & & & & & & & & \\
\hline & & Syzygium sp. & & & & & & & & & \\
\hline
\end{tabular}


Table 1. Cont.

\begin{tabular}{|c|c|c|c|c|c|c|c|c|c|c|c|c|}
\hline \multirow{2}{*}{\multicolumn{2}{|c|}{ Bacterial Model Strains }} & \multirow[b]{2}{*}{ Plant Family ${ }^{1}$} & \multirow[b]{2}{*}{ Plant Species ${ }^{1}$} & \multirow[b]{2}{*}{$\begin{array}{l}\text { Plant Part and } \\
\text { Traditional } \\
\text { Usage }\end{array}$} & \multirow[b]{2}{*}{$\begin{array}{c}\text { Active } \\
\text { Extracts } \\
\text { (or Fraction) }\end{array}$} & \multirow[b]{2}{*}{$\begin{array}{c}\text { Bactericidal } \\
\text { Effect MIC } \\
(\mu \mathrm{g} / \mathrm{mL})\end{array}$} & \multicolumn{4}{|c|}{ Impact on Bacterial Virulence $^{2}$} & \multirow[b]{2}{*}{$\begin{array}{l}\text { Synergy } \\
\text { with } \\
\text { Antibiotics }\end{array}$} & \multirow[b]{2}{*}{ References } \\
\hline & & & & & & & Motility & $\begin{array}{l}\text { Virulence } \\
\text { Factors } \\
\text { Production }\end{array}$ & $\begin{array}{l}\text { Biofilm } \\
\text { Formation }\end{array}$ & QS & & \\
\hline \multirow{10}{*}{ 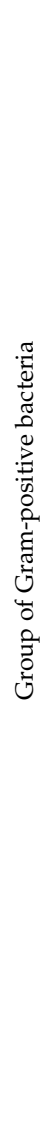 } & \multirow{6}{*}{$\begin{array}{c}\text { B. cereus ATCC } \\
21366\end{array}$} & \multirow{6}{*}{ Myrtaceae } & $\begin{array}{l}\text { Eugenia } \\
\text { erythrophylla } \\
\text { Strey }\end{array}$ & \multirow{6}{*}{$\begin{array}{l}\text { Leaves; } \\
\text { diarrhea, } \\
\text { diabetes, } \\
\text { reproductive } \\
\text { problems, and } \\
\text { respiratory } \\
\text { conditions }\end{array}$} & \multirow{6}{*}{ Acetone } & \multirow{6}{*}{$20-160$} & \multirow{6}{*}{$\mathrm{NC}$} & \multirow{6}{*}{$\mathrm{NC}$} & \multirow{6}{*}{$\searrow$} & \multirow{6}{*}{$\mathrm{NC}$} & \multirow{6}{*}{$\mathrm{NC}$} & \multirow{6}{*}{ [50] } \\
\hline & & & $\begin{array}{c}\text { Eugenia } \\
\text { umtamvunensis } \\
\text { A.E.van Wyk }\end{array}$ & & & & & & & & & \\
\hline & & & $\begin{array}{c}\text { Eugenia capensis } \\
\text { subsp. zeyheri } \\
\text { (Harv.) F.White } \\
\text { [synonym of } \\
\text { Eugenia zeyheri } \\
\text { (Harv.) Harv.] }\end{array}$ & & & & & & & & & \\
\hline & & & $\begin{array}{c}\text { Syzygium legatii } \\
\text { Burtt Davy \& } \\
\text { Greenway }\end{array}$ & & & & & & & & & \\
\hline & & & Syzygium sp. & & & & & & & & & \\
\hline & & & $\begin{array}{c}\text { Syzygium } \\
\text { gerrardii (Harv. } \\
\text { ex Hook.f.) } \\
\text { Burtt Davy }\end{array}$ & & & & & & & & & \\
\hline & \multirow{4}{*}{$\begin{array}{c}\text { E. faecalis ATCC } \\
29212\end{array}$} & \multirow{4}{*}{ Myrtaceae } & $\begin{array}{c}\text { Eugenia } \\
\text { umtamvunensis } \\
\text { A.E.van Wyk }\end{array}$ & \multirow{4}{*}{$\begin{array}{l}\text { Leaves; } \\
\text { diarrhea, } \\
\text { diabetes, } \\
\text { reproductive } \\
\text { problems, and } \\
\text { respiratory } \\
\text { conditions }\end{array}$} & \multirow{4}{*}{ Acetone } & \multirow{4}{*}{$40-160$} & \multirow{4}{*}{$\mathrm{NC}$} & \multirow{4}{*}{$\mathrm{NC}$} & \multirow{4}{*}{$\searrow$} & \multirow{4}{*}{ NC } & \multirow{4}{*}{$\mathrm{NC}$} & \multirow{4}{*}[50]{} \\
\hline & & & $\begin{array}{c}\text { Syzygium } \\
\text { masukuense } \\
\text { (Baker) R.E.Fr. }\end{array}$ & & & & & & & & & \\
\hline & & & $\begin{array}{c}\text { Syzygium legatii } \\
\text { Burtt Davy \& } \\
\text { Greenway }\end{array}$ & & & & & & & & & \\
\hline & & & $\begin{array}{c}\text { Syzygium } \\
\text { gerrardii (Harv. } \\
\text { ex Hook.f.) } \\
\text { Burtt Davy }\end{array}$ & & & & & & & & & \\
\hline
\end{tabular}


Table 1. Cont

\begin{tabular}{|c|c|c|c|c|c|c|c|c|c|c|c|}
\hline \multirow[b]{2}{*}{ Bacterial Model Strains } & \multirow[b]{2}{*}{ Plant Family ${ }^{1}$} & \multirow[b]{2}{*}{ Plant Species ${ }^{1}$} & \multirow[b]{2}{*}{$\begin{array}{l}\text { Plant Part and } \\
\text { Traditional } \\
\text { Usage }\end{array}$} & \multirow{2}{*}{$\begin{array}{l}\text { Active Extracts } \\
\text { (or Fraction) }\end{array}$} & \multirow[b]{2}{*}{$\begin{array}{c}\text { Bactericidal } \\
\text { Effect MIC } \\
(\mu \mathrm{g} / \mathrm{mL})\end{array}$} & \multicolumn{4}{|c|}{ Impact on Bacterial Virulence $^{2}$} & \multirow[b]{2}{*}{$\begin{array}{l}\text { Synergy } \\
\text { with } \\
\text { Antibiotics }\end{array}$} & \multirow[b]{2}{*}{ References } \\
\hline & & & & & & Motility & $\begin{array}{l}\text { Virulence } \\
\text { Factors } \\
\text { Production }\end{array}$ & $\begin{array}{l}\text { Biofilm } \\
\text { Formation }\end{array}$ & QS & & \\
\hline \multirow{2}{*}{$\begin{array}{l}\text { L. monocytogenes } \\
\text { ATCC } 19111\end{array}$} & Fabaceae & $\begin{array}{l}\text { Aspalathus } \\
\text { linearis (Burn.f.) } \\
\text { R. Dahlgren }\end{array}$ & $\begin{array}{c}\text { Leaves; } \\
\text { antioxidant and } \\
\text { antifungal } \\
\text { activities }\end{array}$ & \multirow{2}{*}{$\begin{array}{l}\text { Dichloromethane } \\
\text { /Methanol }\end{array}$} & \multirow[t]{2}{*}{$\mathrm{NC}$} & \multirow[t]{2}{*}{$\mathrm{NC}$} & \multirow[t]{2}{*}{ NC } & \multirow[t]{2}{*}{$\searrow$} & \multirow[t]{2}{*}{ NC } & \multirow[t]{2}{*}{$\mathrm{NC}$} & \multirow[t]{2}{*}{ [58] } \\
\hline & Rutaceae & $\begin{array}{c}\text { Agathosma } \\
\text { betulina (P.J. } \\
\text { Bergius) Pillans }\end{array}$ & $\begin{array}{c}\text { Dried plant } \\
\text { material; urinary } \\
\text { tract infectious }\end{array}$ & & & & & & & & \\
\hline \multirow{6}{*}{$\begin{array}{c}\text { S. aureus ATCC } \\
25923\end{array}$} & Aristolochiaceae & $\begin{array}{l}\text { Hydnora africana } \\
\text { Thumb. }\end{array}$ & $\begin{array}{c}\text { Bark; urinary } \\
\text { tract infections }\end{array}$ & \multirow[b]{2}{*}{ Methanol } & \multirow{6}{*}{$500-4000$} & \multirow{6}{*}{$\mathrm{NC}$} & \multirow[b]{2}{*}{$\searrow$} & \multirow[b]{2}{*}{$\searrow$} & \multirow{6}{*}{ NC } & \multirow{6}{*}{$\mathrm{NC}$} & \multirow{6}{*}{ [44] } \\
\hline & Asparagaceae & $\begin{array}{c}\text { Eucomis } \\
\text { autumnalis } \\
\text { (Mill.) Chitt }\end{array}$ & $\begin{array}{l}\text { Bulb; urinary } \\
\text { tract infections }\end{array}$ & & & & & & & & \\
\hline & Asteraceae & $\begin{array}{c}\text { Baccharoides } \\
\text { adoensis (Sch.Bip. } \\
\text { ex Walp.) H.Rob. } \\
\text { [synonym of } \\
\text { Vernonia adoensis } \\
\text { Sch.Bip. } \\
\text { ex Walp.] }\end{array}$ & $\begin{array}{l}\text { Bark; urinary } \\
\text { tract infections }\end{array}$ & Distilled water & & & $\leftrightarrow$ & $\searrow$ & & & \\
\hline & Fabaceae & $\begin{array}{c}\text { Bauhinia bowkeri } \\
\text { Harv. }\end{array}$ & $\begin{array}{l}\text { Roots; urinary } \\
\text { tract infections }\end{array}$ & Water & & & $\searrow$ & $\leftrightarrow$ & & & \\
\hline & Hypoxidaceae & $\begin{array}{c}\text { Hypoxis } \\
\text { hemerocallidea } \\
\text { Fisch., C.A.Mey. } \\
\text { \& Avé-Lall. }\end{array}$ & $\begin{array}{l}\text { Corm; urinary } \\
\text { tract infections }\end{array}$ & Dichloromethane & & & $\searrow$ & $\searrow$ & & & \\
\hline & Lauraceae & $\begin{array}{l}\text { Cryptocarya } \\
\text { latifolia Sond. }\end{array}$ & $\begin{array}{l}\text { Bark; urinary } \\
\text { tract infections }\end{array}$ & Methanol & & & $\searrow$ & $\leftrightarrow$ & & & \\
\hline
\end{tabular}


Table 1. Cont.

\begin{tabular}{|c|c|c|c|c|c|c|c|c|c|c|c|}
\hline \multirow[b]{2}{*}{ Bacterial Model Strains } & \multirow[b]{2}{*}{ Plant Family $^{1}$} & \multirow[b]{2}{*}{ Plant Species $^{1}$} & \multirow[b]{2}{*}{$\begin{array}{l}\text { Plant Part and } \\
\text { Traditional } \\
\text { Usage }\end{array}$} & \multirow[b]{2}{*}{$\begin{array}{l}\text { Active Extracts } \\
\text { (or Fraction) }\end{array}$} & \multirow[b]{2}{*}{$\begin{array}{c}\text { Bactericidal } \\
\text { Effect MIC } \\
(\mu \mathrm{g} / \mathrm{mL})\end{array}$} & \multicolumn{4}{|c|}{ Impact on Bacterial Virulence $^{2}$} & \multirow[b]{2}{*}{$\begin{array}{l}\text { Synergy } \\
\text { with } \\
\text { Antibiotics }\end{array}$} & \multirow[b]{2}{*}{ References } \\
\hline & & & & & & Motility & $\begin{array}{c}\text { Virulence } \\
\text { Factors } \\
\text { Production }\end{array}$ & $\begin{array}{l}\text { Biofilm } \\
\text { Formation }\end{array}$ & QS & & \\
\hline \multirow{6}{*}{$\begin{array}{c}\text { S. aureus ATCC } \\
29213\end{array}$} & \multirow{6}{*}{ Myrtaceae } & $\begin{array}{l}\text { Eugenia } \\
\text { erythrophylla } \\
\text { Strey }\end{array}$ & \multirow{6}{*}{$\begin{array}{l}\text { Leaves; } \\
\text { diarrhea, } \\
\text { diabetes, } \\
\text { reproductive } \\
\text { problems, and } \\
\text { respiratory } \\
\text { conditions }\end{array}$} & \multirow{6}{*}{ Acetone } & \multirow{6}{*}{$40-160$} & \multirow{6}{*}{$\mathrm{NC}$} & \multirow{6}{*}{ NC } & \multirow{6}{*}{$\searrow$} & \multirow{6}{*}{ NC } & \multirow{6}{*}{$\mathrm{NC}$} & \multirow{6}{*}[50]{} \\
\hline & & $\begin{array}{c}\text { Eugenia } \\
\text { umtamvunensis } \\
\text { A.E.van Wyk }\end{array}$ & & & & & & & & & \\
\hline & & $\begin{array}{c}\text { Eugenia capensis } \\
\text { subsp. zeyheri } \\
\text { (Harv.) F.White } \\
\text { [synonym of } \\
\text { Eugenia zeyherii } \\
\text { (Harv.) Harv.] }\end{array}$ & & & & & & & & & \\
\hline & & $\begin{array}{c}\text { Syzygium legatii } \\
\text { Burtt Davy \& } \\
\text { Greenway }\end{array}$ & & & & & & & & & \\
\hline & & $\begin{array}{c}\text { Syzygium } \\
\text { masukuense } \\
\text { (Baker) R.E.Fr. }\end{array}$ & & & & & & & & & \\
\hline & & $\begin{array}{c}\text { Syzygium } \\
\text { gerrardii (Harv. } \\
\text { ex Hook.f.) } \\
\text { Burtt Davy }\end{array}$ & & & & & & & & & \\
\hline \multirow{5}{*}{$\begin{array}{c}\text { S. mutans ATCC } \\
25175\end{array}$} & Asteraceae & $\begin{array}{l}\text { Tarchonanthus } \\
\text { camphoratus } L \text {. }\end{array}$ & $\begin{array}{l}\text { Leaves; } \\
\text { toothache }\end{array}$ & $\begin{array}{l}\text { Dichloromethane } \\
\text { /methanol }\end{array}$ & \multirow{5}{*}{$500-1000$} & \multirow{5}{*}{$\mathrm{NC}$} & \multirow{5}{*}{ NC } & \multirow{5}{*}{$\searrow$} & \multirow{5}{*}{ NC } & \multirow{5}{*}{$\mathrm{NC}$} & \multirow{5}{*}{ [59] } \\
\hline & Bignoniaceae & $\begin{array}{l}\text { Tecoma capensis } \\
\text { (Thumb.) Lindl., }\end{array}$ & $\begin{array}{c}\text { Leaves; rubbed } \\
\text { onto bleeding }\end{array}$ & $\begin{array}{c}\text { Dichloromethane } \\
\text { /methanol }\end{array}$ & & & & & & & \\
\hline & Euphorbiaceae & $\begin{array}{l}\text { Spyrostachys } \\
\text { africana Sond. }\end{array}$ & $\begin{array}{l}\text { Leaves; } \\
\text { toothache } \\
\text { remedy }\end{array}$ & $\begin{array}{l}\text { Dichloromethane } \\
\text { /methanol }\end{array}$ & & & & & & & \\
\hline & Fabaceae & $\begin{array}{c}\text { Vachellia karroo } \\
\text { (Hayne) Banfi \& } \\
\text { Galasso } \\
\text { [synonym of } \\
\text { Acacia karroo } \\
\text { Hayne] }\end{array}$ & $\begin{array}{l}\text { Leaves; oral } \\
\text { thrush }\end{array}$ & $\begin{array}{l}\text { Dichloromethane } \\
\text { /methanol }\end{array}$ & & & & & & & \\
\hline & Fabaceae & $\begin{array}{l}\text { Erythrina } \\
\text { lysistemon } \\
\text { Hutch. }\end{array}$ & Bark; toothache & $\begin{array}{l}\text { Dichloromethane } \\
\text { /methanol }\end{array}$ & & & & & & & \\
\hline
\end{tabular}


Table 1. Cont.

\begin{tabular}{|c|c|c|c|c|c|c|c|c|c|c|c|c|}
\hline \multirow{2}{*}{\multicolumn{2}{|c|}{ Bacterial Model Strains }} & \multirow[b]{2}{*}{ Plant Family $^{1}$} & \multirow[b]{2}{*}{ Plant Species $^{1}$} & \multirow[b]{2}{*}{$\begin{array}{c}\text { Plant Part and } \\
\text { Traditional } \\
\text { Usage }\end{array}$} & \multirow[b]{2}{*}{$\begin{array}{c}\text { Active } \\
\text { Extracts } \\
\text { (or Fraction) }\end{array}$} & \multirow[b]{2}{*}{$\begin{array}{c}\text { Bactericidal } \\
\text { Effect MIC } \\
(\mu \mathrm{g} / \mathrm{mL})\end{array}$} & \multicolumn{4}{|c|}{ Impact on Bacterial Virulence $^{2}$} & \multirow[b]{2}{*}{$\begin{array}{l}\text { Synergy } \\
\text { with } \\
\text { Antibiotics }\end{array}$} & \multirow[b]{2}{*}{ References } \\
\hline & & & & & & & Motility & $\begin{array}{l}\text { Virulence } \\
\text { Factors } \\
\text { Production }\end{array}$ & $\begin{array}{l}\text { Biofilm } \\
\text { Formation }\end{array}$ & QS & & \\
\hline \multirow{10}{*}{ 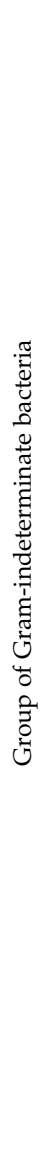 } & \multirow{10}{*}{$\begin{array}{c}\text { Mycobacterium } \\
\text { smegmatis MC155 } \\
\text { M.tuberculosis } \\
\text { H37Rv ATCC } 27264\end{array}$} & Asphodelaceae & $\begin{array}{c}\text { Kumara plicatilis } \\
\text { (L.) G.D.Rowley } \\
\text { [synonym of } \\
\text { Aloe plicatilis (L.) } \\
\text { Mill.] }\end{array}$ & Roots; diarrhea & \multirow{10}{*}{ Ethanol } & \multirow{10}{*}{$31-1000$} & \multirow{10}{*}{$\mathrm{NC}$} & \multirow{10}{*}{$\mathrm{NC}$} & \multirow{10}{*}{$\searrow$} & \multirow{10}{*}{ NC } & \multirow{10}{*}{ NC } & \multirow{10}{*}{ [60] } \\
\hline & & \multirow{4}{*}{ Asparagaceae } & $\begin{array}{l}\text { Dracaena } \\
\text { aletriformis } \\
\text { (Haw.) Bos }\end{array}$ & $\begin{array}{l}\text { Leaves; chest } \\
\text { pains }\end{array}$ & & & & & & & & \\
\hline & & & $\begin{array}{l}\text { Dracaena draco } \\
\text { (L.) L. }\end{array}$ & $\begin{array}{l}\text { Leaves; fever, } \\
\text { respiratory } \\
\text { ailments }\end{array}$ & & & & & & & & \\
\hline & & & $\begin{array}{l}\text { Eucomis } \\
\text { vandermerwei } \\
\text { Verd. }\end{array}$ & $\begin{array}{l}\text { Leaves; } \\
\text { anti-inflammatory }\end{array}$ & & & & & & & & \\
\hline & & & $\begin{array}{l}\text { Merwilla plumbea } \\
\text { (Lindl.) Speta }\end{array}$ & $\begin{array}{l}\text { Leaves; chest } \\
\text { pains and lung } \\
\text { infections }\end{array}$ & & & & & & & & \\
\hline & & Euphorbiaceae & $\begin{array}{c}\text { Euphorbia } \\
\text { tirrucalli } \mathrm{L} .\end{array}$ & Stems; cough & & & & & & & & \\
\hline & & Icacinaceae & $\begin{array}{l}\text { Cassinopsis } \\
\text { ilicifolia } \\
\text { (Hochst.) } \\
\text { Sleumer }\end{array}$ & $\begin{array}{l}\text { Leaves and } \\
\text { stem; stomach } \\
\text { ailments }\end{array}$ & & & & & & & & \\
\hline & & \multirow{2}{*}{ Lamiaceae } & $\begin{array}{l}\text { Leonotis leonurus } \\
\text { (L) R.Br. }\end{array}$ & $\begin{array}{l}\text { Leaves and } \\
\text { stem; fever, } \\
\text { headache, and } \\
\text { cough }\end{array}$ & & & & & & & & \\
\hline & & & $\begin{array}{c}\text { Salvia aurea } \mathrm{L} \text {. } \\
\text { [synonym of } \\
\text { Salvia africana } \\
\text { lutea } \mathrm{L} \text {.] }\end{array}$ & $\begin{array}{l}\text { Leaves and } \\
\text { stem; cough, } \\
\text { colds, and } \\
\text { bronchitis }\end{array}$ & & & & & & & & \\
\hline & & Malpighiaceae & $\begin{array}{c}\text { Sphedamnocarpus } \\
\text { pruriens (A. } \\
\text { Juss.) Szyszył }\end{array}$ & $\begin{array}{l}\text { Seeds and roots; } \\
\text { snake bites }\end{array}$ & & & & & & & & \\
\hline
\end{tabular}


Table 1. Cont.

\begin{tabular}{|c|c|c|c|c|c|c|c|c|c|c|c|}
\hline \multirow[b]{2}{*}{ Bacterial Model Strains } & \multirow[b]{2}{*}{ Plant Family ${ }^{1}$} & \multirow[b]{2}{*}{ Plant Species ${ }^{1}$} & \multirow[b]{2}{*}{$\begin{array}{l}\text { Plant Part and } \\
\text { Traditional } \\
\text { Usage }\end{array}$} & \multirow[b]{2}{*}{$\begin{array}{c}\text { Active } \\
\text { Extracts } \\
\text { (or Fraction) }\end{array}$} & \multirow[b]{2}{*}{$\begin{array}{c}\text { Bactericidal } \\
\text { Effect MIC } \\
(\mu \mathrm{g} / \mathrm{mL})\end{array}$} & \multicolumn{4}{|c|}{ Impact on Bacterial Virulence ${ }^{2}$} & \multirow[b]{2}{*}{$\begin{array}{l}\text { Synergy } \\
\text { with } \\
\text { Antibiotics }\end{array}$} & \multirow[b]{2}{*}{ References } \\
\hline & & & & & & Motility & $\begin{array}{l}\text { Virulence } \\
\text { Factors } \\
\text { Production }\end{array}$ & $\begin{array}{l}\text { Biofilm } \\
\text { Formation }\end{array}$ & QS & & \\
\hline & Orobanchaceae & $\begin{array}{c}\text { Alectra } \\
\text { sessiliflora (Vahl) } \\
\text { Kuntze }\end{array}$ & Roots; diarrhea & & & & & & & & \\
\hline & Proteaceae & $\begin{array}{c}\text { Faurea saligna } \\
\text { Harv. }\end{array}$ & Leaves; diarrhea & & & & & & & & \\
\hline & Solanaceae & $\begin{array}{l}\text { Withania } \\
\text { somnifera }(\mathrm{L}) \\
\text { Dunal }\end{array}$ & $\begin{array}{c}\text { Leaves and } \\
\text { stem; fever and } \\
\text { anti-inflammatory }\end{array}$ & & & & & & & & \\
\hline & Typhaceae & $\begin{array}{c}\text { Typha capensis } \\
\text { (Rohrb.) N.E.Br. }\end{array}$ & $\begin{array}{l}\text { Leaves and } \\
\text { roots; diarrhea }\end{array}$ & & & & & & & & \\
\hline
\end{tabular}

${ }^{1}$ All plant names and families were verified through the Medicinal Plant Names Services (MPNS) of Kew Royal Botanic Gardens (https://www.kew.org/science/our-science/scienceservices/medicinal-plant-names-services) and, if not described in, MPNS through the Plant List portal (http://www.theplantlist.org/); ${ }^{2} /:$ Promotion; $\searrow$ : Inhibition; $\leftrightarrow:$ no impact; NC: not communicated. 


\subsection{Activities on Gram-Negative Bacteria}

Various South African medicinal plants have been widely investigated for their antivirulence activities against various Gram-negative bacteria:

(i) The hexanic extract from South African Kigelia africana (Lam.) Benth. (Fruits, Bignoniaceae) used to treat dysentery, reduces the production of violacein in C. violaceum ATCC 12472 by $65 \%$ when tested at $660 \mu \mathrm{g} / \mathrm{mL}$ [43]. Additionally, this extract interferes with the QS mechanism in A. tumefaciens by affecting the luxI synthase gene and the LuxR transcriptional regulator of autoinducers;

(ii) South African plants, used to treat urinary tract infections, have been studied by Baloyi et al. [44] for their effects on the production of violacein in C. violaceum ATCC 12472. At a final concentration of $330 \mu \mathrm{g} / \mathrm{mL}$, the extracts of Cenchrus ciliaris L. (bark; methanol; Poaceae), Cryptocarya latifolia Sond. (bark; methanol; Lauraceae), Eucomis autumnalis (Mill.) Chitt. (bulb; methanol; Aspaagaceae), Hydnora africana Thumb. (bark; methanol; Aristolochiaceae), Hypoxis hemerocallidea Fisch., C.A.Mey. \& Avé-Lall. (corme; dichlorométhane; Hypoxidaceae), Rhoicissus tridentata (L.f.) Wild \& R.B. Drumm (root; methanol; Vitaceae), Baccharoides adoensis (Sch.Bip. ex Walp.) H.Rob. (synonym of Vernonia adoensis Sch.Bip. ex Walp.) (bark; aqueous; Asteraceae), Bauhinia bowkeri Harv. (root; aqueous; Fabaceae) inhibit the production of violacein in C. violaceum ATCC 12472 (from 4 to 43\% inhibition);

(iii) Plants from the Myrtaceae family, endemic to South Africa and traditionally used to treat different ailments such as diarrhea, diabetes, reproductive problems, and respiratory diseases, have been investigated for their antibiofilm activity against various Gram-negative bacteria, including P. aeruginosa ATCC 27853, Salmonella ser. typhimurium ATCC 39183, and E. coli ATCC 25922 [50]. It has been highlighted that acetone extracts of leaves from different Syzygium and Eugenia species, particularly S. legatii Burtt Davy \& Greenway and E. erythrophylla Strey, at $1000 \mu \mathrm{g} / \mathrm{mL}$ reduce biofilm formation (from 59-100\% inhibition) but were unable to destroy pre-formed biofilms. These extracts exert in planktonic growth condition, a Minimal Inhibitory Concentration (MIC) values ranging from 40 to $310 \mu \mathrm{g} / \mathrm{mL}$ and relatively low cytotoxicity towards kidney epithelial cells (Vero) as concentrations of 140 to $1140 \mu \mathrm{g} / \mathrm{mL}$ inhibit cell viability by $50 \%$ ( $\left.\mathrm{LC}_{50}\right)$; this indicates potentially safe herbal products;

(iv) The ethanolic extract of the leaves of Lessertia frutescences (L.) Goldblatt \& J.C.Manning (synonym of Sutherlandia frutescens (L) R.Br.) (Fabaceae), showed antibiofilm activity (90\% inhibition) in P. aeruginosa ATCC 35032 and inhibition (>80\%) of pyocyanin and LasB elastase [52].

Finally, (v) the methanolic extract of the South African plant Sclerocarya birrea (A.Rich.) Hoch. (trunk bark; Anacardiaceae) has been proposed to exhibit anti-QS activity as it inhibits the production of pyoverdine, protease and motility as well as biofilm formation (78\% inhibition) in P. aeruginosa MTCC 2453 at the concentration of $100 \mu \mathrm{g} / \mathrm{mL}$ [53].

Plants from Western Africa, and particularly seven medicinal plants from Burkina Faso, have been also investigated for their impact on C. violaceum and P. aeruginosa QS mechanism and on P. aeruginosa biofilm formation; antivirulence activities of these Burkinabe plants are summarized in Table 2. 
Table 2. Antivirulence activities of Burkinabe medicinal plants against Gram-negative bacteria.

\begin{tabular}{|c|c|c|c|c|c|c|c|}
\hline $\begin{array}{c}\text { Burkinabe } \\
\text { Medicinal Plant }\end{array}$ & Plant Part & $\begin{array}{l}\text { Tested Extract and } \\
\text { Concentration }\end{array}$ & $\begin{array}{c}\text { Production of } \\
\text { Violacein in } C \text {. } \\
\text { violaceum CV026 }\end{array}$ & $\begin{array}{c}\text { Production of } \\
\text { Pyocyanin in } P . \\
\text { aeruginosa PAO }\end{array}$ & $\begin{array}{c}\text { Production of } \\
\text { Elastase in } P . \\
\text { aeruginosa PAO1 }\end{array}$ & $\begin{array}{c}\text { Production of } \\
\text { Biofilm in } P . \\
\text { aeruginos } \text { PAO }^{1}\end{array}$ & References \\
\hline $\begin{array}{l}\text { Acacia dudgeoni } \\
\text { Craib. ex Holl. }\end{array}$ & Stem bark & $\begin{array}{c}\text { Methanol } \\
50-400 \mu \mathrm{g} / \mathrm{mL}^{2,3}\end{array}$ & $-25 \%$ to $-69 \%$ & $-33 \%$ to $-66 \%$ & NC & $-25 \%$ to $-59 \%$ & {$[61]$} \\
\hline \multirow{2}{*}{$\begin{array}{l}\text { Balanites aegyptiaca } \\
\text { (L.) Delille. }\end{array}$} & Leafy galls $^{1}$ & $\begin{array}{c}\text { Methanol } \\
100 \mu \mathrm{g} / \mathrm{mL}^{2}\end{array}$ & $-10 \%$ & $-15 \%$ & NC & $-33 \%$ & \multirow{2}{*}{ [48] } \\
\hline & Stem bark & $\begin{array}{c}\text { Methanol } \\
100 \mu \mathrm{g} / \mathrm{mL}^{2}\end{array}$ & $-15 \%$ & $-20 \%$ & NC & $-20 \%$ & \\
\hline $\begin{array}{c}\text { Crossopteryx } \\
\text { febrifuga (Afzel ex } \\
\text { G. Don) Benth }\end{array}$ & Leave and stem & $\begin{array}{c}\text { Methanol } \\
100 \mu \mathrm{g} / \mathrm{mL}^{2}\end{array}$ & $\mathrm{NC}$ & $-52 \%$ & $-48 \%$ & NC & [46] \\
\hline $\begin{array}{l}\text { Terminalia leiocarpa } \\
\text { (DC.) Baill. } \\
\text { [synonym of } \\
\text { Anogeissus } \\
\text { leiocarpus (DC) } \\
\text { Guill. et Perr.] }\end{array}$ & Stem bark & $\begin{array}{c}\text { Methanol } \\
100 \mu \mathrm{g} / \mathrm{mL}^{2}\end{array}$ & $-50 \%$ & $-66 \%$ & NC & $\mathrm{NC}$ & [57] \\
\hline $\begin{array}{l}\text { Terminalia } \\
\text { macroptera Guill. } \\
\text { and Perr. }\end{array}$ & Stem bark & $\begin{array}{c}\text { Methanol } \\
100 \mu \mathrm{g} / \mathrm{mL}^{2}\end{array}$ & $-35 \%$ & $-50 \%$ & NC & $-30 \%$ & [48] \\
\hline $\begin{array}{c}\text { Vachellia seyal } \\
\text { (Delile) } \\
\text { P.J.H.Hurter } \\
\text { [synonym of } \\
\text { Acacia seyal Delile] }\end{array}$ & Bark & $\begin{array}{c}\text { Methanol } \\
50-800 \mu \mathrm{g} / \mathrm{mL}^{2,3}\end{array}$ & $-25 \%$ to $-97 \%$ & $-22 \%$ to $-86 \%$ & $-8 \%$ to $-56 \%$ & $\begin{array}{l}\text { At } 800 \mu \mathrm{g} / \mathrm{mL}: \\
-69 \%\end{array}$ & [47] \\
\hline $\begin{array}{l}\text { Zanthoxylum } \\
\text { zanthoxyloides } \\
\text { (Lam) Zepern. } \\
\text { and Timler }\end{array}$ & Stem bark & $\begin{array}{c}\text { Methanol } \\
100 \mu \mathrm{g} / \mathrm{mL}^{2}\end{array}$ & $\mathrm{NC}$ & $-28 \%$ & $-15 \%$ & NC & [46] \\
\hline
\end{tabular}

${ }^{1}$ produced on leaves, following insect attack; ${ }^{2}$ sub-inhibitory concentrations; ${ }^{3}$ sub-inhibitory concentrations: $<800 \mu \mathrm{g} / \mathrm{mL}$. 
These include Acacia dudgeoni Craib. ex Holl (Mimosaceae), used in the treatment of diarrhea and childhood dysentery [45,61]; Balanites aegyptiaca (L.) Delille (Zygophyllaceae) [48], traditionally used for the treatment of respiratory tract diseases, skin diseases, and wounds; Crossopteryx febrifuga (Afzel ex G. Don) Benth. (Rubiaceae) used in the treatment of various infectious diseases such as typhoid fever, respiratory infections, infected wounds, and dental diseases [46]; Terminalia leiocarpa (DC.) Baill. (synonym of Anogeissus leiocarpus (DC) Guill. et Perr.) (Combretaceae), also used to treat respiratory diseases and wounds [57]; Terminalia macroptera Guill. \& Perr. (Combretaceae) [48], traditionally used for the treatment of respiratory tract diseases, skin diseases and wounds; Vachellia seyal (Delile) P.J.H.Hurter (synonym of Acacia seyal Delile) Del (Fabaceae) [47] traditionally used to treat toothache, dysentery, and burns [62] with reported potent antimicrobial activity [63]; and Zanthoxylum zanthoxyloides (Lam) Zepern. and Timler (Rutaceae) also used to treat typhoid fever, respiratory infections, infected wounds, and dental diseases [46].

Plants from Eastern Africa have been also investigated for their QQ properties in a E. coli model. About 25 medicinal plant extracts (roots, bark, and leaves; ethanol 50\% v/v) used in southwestern Kenya to treat gastrointestinal and urinary tract infections were tested against a transformed E. coli Top 10 reporter QS strain that expresses green fluorescent protein (GFP) when induced by exogenous AHLs (3-oxo-C6HSL). Interestingly, the extracts of Vachellia gerrardii (Benth.) P.J.H.Hurter (synonym of Acacia gerrardii Benth) and Elaeodendron buchananii (Loes.) Loes. barks, at $1000 \mu \mathrm{g} / \mathrm{mL}$ reduce the reporter GFP expression (up to 50\% inhibition) without any effect on the E. coli biofilm formation [51]. In the same line, two Ethiopian antimicrobial medicinal plants have been reported to exert anti-QS without affecting bacterial viability; the root methanolic extract of Albizia schimperiana Oliv. (Fabaceae) and seed petroleum ether extract of Justicia schimperiana (Hochst. ex Nees) T. Anderson (Acanthaceae) at $6500 \mu \mathrm{g} / \mathrm{mL}$ interfere with cell-to-cell communication, most likely by interacting with the 3-oxo-C6-HSL signaling pathway in E. coli reporter strain AI1-QQ.1 [49].

For almost 10 years, antivirulence activities of endemic plants from Madagascar have been regularly reported. Indeed, the bark of D. pervillei Vakte and D. trichocarpa Baker (Fabaceae; hexane extracts tested at $300 \mu \mathrm{g} / \mathrm{mL}$ ) inhibit the production of $P$. aeruginosa virulence factors pyocyanin and elastase by $43 \%$ and $25 \%$, respectively, and the expression of QS-related (lasI, lasR, rhlI, and rhlR) and QS-regulated (lasB and $r h l A$ ) genes [64]. Further investigations on the hexane bark extract of D. trichocarpa, traditionally used to treat various ailments—such as laryngitis, diarrhea, and rheumatic pains-led to the generation of active fractions which exert anti-QS and/or antibiofilm activities. Particularly, an active fraction exerts antibiofilm activities at $200 \mu \mathrm{g} / \mathrm{mL}(63 \%$ inhibition) without affecting bacterial viability or QS mechanism of $P$. aeruginosa PAO1. The inhibition of biofilm formation is probably linked to a reduction in flagellar-dependent motilities (swimming and swarming) as well as in exopolysaccharides production [56]. In Madagascar, a mixture of Tephrosia purpurea L. (Fabaceae) and Buddleja madagascariensis Lam (Buddlejaceae) macerated in cow dung manure is traditionally used as a phytotreatment against potato crops diseases such as potato leaf spots caused by the phytophatogen R. solanacearum [65]. The study of their antibacterial effects demonstrated that the methanolic extracts of both plants, tested at $100 \mu \mathrm{g} / \mathrm{mL}$, reduce the expression of P. aeruginosa PAO1 QS-regulated lasB (45\% and 52\% inhibition, respectively) and $r h l A$ (32\% and 33\% inhibition, respectively) genes; but only T. purpurea extracts exhibit antibiofilm activities against P. aeruginosa PAO1 and R. solanacearum (52\% and $30 \%$ inhibition, respectively) without affecting bacterial growth [55].

Finally, the dichloromethane extract of Cordia gilletii De Wild (Boraginaceae) root barks, medicinal plant from the Democratic Republic of Congo, a plant known for bactericidal activities against pathogenic microorganisms such as E. coli [66], was also found to quench the production of pyocyanin, to inhibit the expression of several QS-regulated genes (i.e., lasB, rhlA, lasI, lasR, rhlI, and $r h l R ; 35 \%, 40 \%, 24 \%, 25 \%, 52 \%$, and 23\% inhibition, respectively) and to reduce biofilm formation (21\% inhibition) in P. aeruginosa PAO1 without affecting its viability [54]. 


\subsection{Activities on Gram-Positive Bacteria}

To date, only South African plants have been investigated for their antivirulence activities against Gram-positive bacteria:

(i) the extracts (concentration, $330 \mu \mathrm{g} / \mathrm{mL}$ ) from Cenchrus ciliaris L. (bark; methanol; Poaceae), Eucomis autumnalis (Mill.) Chitt. (bulb; methanol; Asparagaceae), Hypoxis hemerocallidea Fisch., C.A.Mey. \& Avé-Lall. (corme; dichloromethane; Hypoxidaceae), Bacharoides adoensis (Sch.Bip. ex Walp.) H.Rob. [synonym of Vernonia adoensis Sch. Bip. ex Walp.] (bark; water; Asteraceae), which are all used to treat urinary tract infections, inhibit biofilm formation (by 21-38\%) in S. aureus ATCC 25923 [44];

(ii) the acetone leaves extracts of different Syzygium and Eugenia species at $1000 \mu \mathrm{g} / \mathrm{mL}$ present antibiofilm activities against S. aureus ATCC 29213, E. faecalis ATCC 29212, and B. cereus ATCC 21366 [43]. Particularly, the extract of S. gerrardii (Harv. ex Hook.f.) Burtt Davy had the capacity to reduce biofilm formation in all tested strains (68-100\% inhibition) and to destroy pre-formed biofilms (69-100\% biofilm dispersion);

(iii) the dichloromethane/methanol extracts of plants traditionally used to treat oral infections, including Vachellia karroo (Hyane) Banfi \& Galasso (synonym of Acacia karroo Hayne) (leaves; Fabaceae), Erythrina lysistemon Hutch (bark; Fabaceae), Spyrostachys africana Sond. (leaves; Euphorbiaceae), Tecoma capensis (Thumb.) Lindl., (leaves; Bignoniaceae) and Tarchonanthus camphoratus L. (leaves; Asteraceae), at a concentration of $250 \mu \mathrm{g} / \mathrm{mL}$, showed antibiofilm activity against S. mutans ATCC 25175, known to be responsible for dental caries, with 59\%, 68\%, 86\%, 52\%, and 54\% inhibition, respectively [59];

(iv) when the L. monocytogenes ATCC 19111 is grown in the presence of $1000 \mu \mathrm{g} / \mathrm{mL}$ of dichloromethane/methanol leaves extract of Agathosma betulina (P.J. Bergius) Pillans, (Rutaceae), and Aspalathus linearis (Burm.f.) R. Dahlgren (Fabaceae), plants exclusively found in South Africa, biofilm formation reduction was observed with an inhibition rate of $20 \%$ and $75 \%$, respectively [58].

\subsection{Activities on Gram-Indeterminate Bacteria}

Recently, the ethanolic extracts from plants belonging to several South African Medicinal plants have been shown to exert antibiofilm activity in Mycobacterium smegmatis MC155, a Gram-indeterminate bacteria [60]. Among the species, Alectra sessiflora (Vahl) Kuntze (root; Orobranchaceae), Eucomis vandermerwei Verd. (leaves; Asparagaceae), Euphorbia tirrucalli L. (Stem; Euphorbiaceae), Leonotis leonorus (L.) R.Br (leaves and stems; Lamiaceae), Salvia africana lutea L. (leaves and stems; Lamiaceae), Sphedamnocarpus pruriens (A. Juss.) Szyszył. (seeds and root; Mapighiaceae), and Withania somnifera (L) Dunal (leaves and stems, Solanaceae) reduce biofilm formation by 50\% in M. smegmatis MC155, at the concentration of $221 \mu \mathrm{g} / \mathrm{mL}, 266 \mu \mathrm{g} / \mathrm{mL}, 280 \mu \mathrm{g} / \mathrm{mL}, 50 \mu \mathrm{g} / \mathrm{mL}, 95 \mu \mathrm{g} / \mathrm{mL}, 62 \mu \mathrm{g} / \mathrm{mL}$, and $212 \mu \mathrm{g} / \mathrm{mL}$, respectively. According to the same study, Kumara plicatilis (L.) G.D.Rowley (synonym of Aloe plicatilis (L.) Mill.) (roots; Asphodelaceae), Cassinopsis ilicifolia (Hochst.) Sleumer (leaves and roots; Icacinaceae), Dracaena aletriformis (Haw.) Bos, (leaves; Asparagaceae), Dracaena draco (L.) L. (leaves; Asparagaceae), Faurea saligna Harv. (leaves; Proteaceae), Merwilla plumbea (Lindl.) Speta (leaves; Asparagaceae), Typha capensis (Rohrb.) N.E.Br (leaves and roots; Typhaceae) showed reduction of biofilm formation by $50 \%$ in M. smegmatis MC155 at concentrations > $500 \mu \mathrm{g} / \mathrm{mL}$. The leaves ethanol extract of Salvia aurea L. (synonym of Salvia africana lutea L.) (Lamiaceae) and seed ethanol extract of Sphedamnocarpus pruriens (A. Juss.) (Malpighiaceae) showed inhibition of M. tuberculosis biofilm formation by $50 \%$ at concentrations of 95 and $62 \mu \mathrm{g} / \mathrm{mL}$, respectively. Both showed antimycobacterial activity with MIC values of 31 and $62 \mu \mathrm{g} / \mathrm{mL}$, respectively, with low cytotoxicity $\left(\mathrm{LC}_{50}>80 \mu \mathrm{g} / \mathrm{mL}\right.$ ) towards U937 monocytes cells [60].

\section{Compounds Isolated from African Plants with Antivirulence Activities}

Natural compounds isolated from African plants with antivirulence activities, summarized in Table 3, are exclusively phenolic and terpenoid-based compounds and exert their activity against different bacterial strains. 
Table 3. Natural compounds with antivirulence activities isolated from African medicinal plants.

\begin{tabular}{|c|c|c|c|c|c|c|c|c|c|c|c|c|c|}
\hline \multirow{2}{*}{\multicolumn{2}{|c|}{$\begin{array}{l}\text { Bacterial Model } \\
\text { Strains }\end{array}$}} & \multirow{3}{*}{$\begin{array}{c}\text { Plant Family }^{1} \\
\text { Moraceae }\end{array}$} & \multirow{3}{*}{$\begin{array}{c}\text { Plant Species }^{1} \\
\begin{array}{c}\text { Ficus sansibarica } \\
\text { Warb. }\end{array}\end{array}$} & \multirow{3}{*}{$\begin{array}{l}\text { Compound } \\
\text { Epicatechin }\end{array}$} & \multirow{3}{*}{ Chemical Structure } & \multirow{3}{*}{$\begin{array}{c}\text { Plant Part and } \\
\text { Traditional Usage } \\
\begin{array}{c}\text { Leaves and fruits; } \\
\text { wound, dysentery, } \\
\text { diarrhea, tuberculosis }\end{array}\end{array}$} & \multirow{3}{*}{$\begin{array}{c}\begin{array}{c}\text { Bactericidal } \\
\text { Effect MIC } \\
(\mu \mathrm{g} / \mathrm{mL})\end{array} \\
8000\end{array}$} & \multicolumn{4}{|c|}{ Impact on Bacterial Virulence ${ }^{2}$} & \multirow[b]{2}{*}{$\begin{array}{c}\text { Synergy } \\
\text { with } \\
\text { Antibiotics }\end{array}$} & \multirow[b]{2}{*}{ References } \\
\hline & & & & & & & & Motility & $\begin{array}{l}\text { Virulence } \\
\text { Factors } \\
\text { Production }\end{array}$ & $\begin{array}{c}\text { Biofilm } \\
\text { Formation }\end{array}$ & QS & & \\
\hline \multirow{9}{*}{ 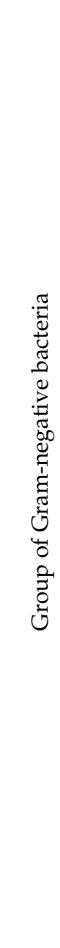 } & $\begin{array}{l}\text { E. coli } \\
\text { ATCC } \\
25922\end{array}$ & & & & & & & NC & $\mathrm{NC}$ & $\searrow$ & $\mathrm{NC}$ & $\mathrm{NC}$ & [67] \\
\hline & \multirow{2}{*}{$\begin{array}{c}\text { C. } \\
\text { violaceum } \\
\text { CV026 }\end{array}$} & Combretaceae & $\begin{array}{l}\text { Combretum } \\
\text { albiflorum (Tul.) } \\
\text { Jongkind }\end{array}$ & Catechin & & $\begin{array}{c}\text { Bark; bacterial } \\
\text { infection, fever, } \\
\text { pneumonia }\end{array}$ & 2000 & NC & $\searrow$ & $\mathrm{NC}$ & $\searrow$ & $\mathrm{NC}$ & [68] \\
\hline & & \multirow[t]{2}{*}{ Combretaceae } & \multirow[t]{2}{*}{$\begin{array}{l}\text { Guiera senegalensis } \\
\text { J. F. Gmel }\end{array}$} & \multirow[t]{2}{*}{$\begin{array}{l}\text { Methyl } \\
\text { Gallate }\end{array}$} & & \multirow[t]{2}{*}{$\begin{array}{c}\text { Bark; cough, } \\
\text { dysentery, malaria }\end{array}$} & 64 & NC & $\searrow$ & NC & $\searrow$ & $\mathrm{NC}$ & \multirow[t]{2}{*}{ [69] } \\
\hline & \multirow{6}{*}{$\begin{array}{c}P . \\
\text { aeruginosa } \\
\text { PAO1 }\end{array}$} & & & & & & 512 & $\searrow$ & $\searrow$ & $\searrow$ & $\searrow$ & NC & \\
\hline & & Combretaceae & $\begin{array}{l}\text { Combretum } \\
\text { albiflorum (Tul.) } \\
\text { Jongkind }\end{array}$ & Catechin & & $\begin{array}{l}\text { Bark; bacterial } \\
\text { infection, fever, } \\
\text { pneumonia }\end{array}$ & 2000 & $\mathrm{NC}$ & $\searrow$ & $\searrow$ & $\searrow$ & $\mathrm{NC}$ & {$[68]$} \\
\hline & & Fabaceae & $\begin{array}{c}\text { Dalbergia } \\
\text { trichocarpa Baker }\end{array}$ & $\begin{array}{l}\text { Oleanolic } \\
\text { aldehyde } \\
\text { coumarate }\end{array}$ & & $\begin{array}{l}\text { Bark; laryngitis, } \\
\text { diarrhea }\end{array}$ & 4000 & $\searrow$ & $\searrow$ & $\searrow$ & $\searrow$ & yes & [5] \\
\hline & & Lamiaceae & $\begin{array}{c}\text { Platostoma } \\
\text { rotundifolium } \\
\text { (Briq.) A. J. Paton }\end{array}$ & $\beta$-sitosterol & & $\begin{array}{l}\text { Aerial part; bacterial } \\
\text { diseases }\end{array}$ & 4000 & $\nearrow$ & $\searrow$ & $\searrow$ & $\searrow$ & yes & [70] \\
\hline & & & & Cassipourol & & & 4000 & $\nearrow$ & $\searrow$ & $\searrow$ & $\searrow$ & yes & \\
\hline & & & & $\alpha$-amyrin & & & 4000 & $\nearrow$ & $\searrow$ & $\searrow$ & $\leftrightarrow$ & yes & \\
\hline
\end{tabular}


Table 3. Cont

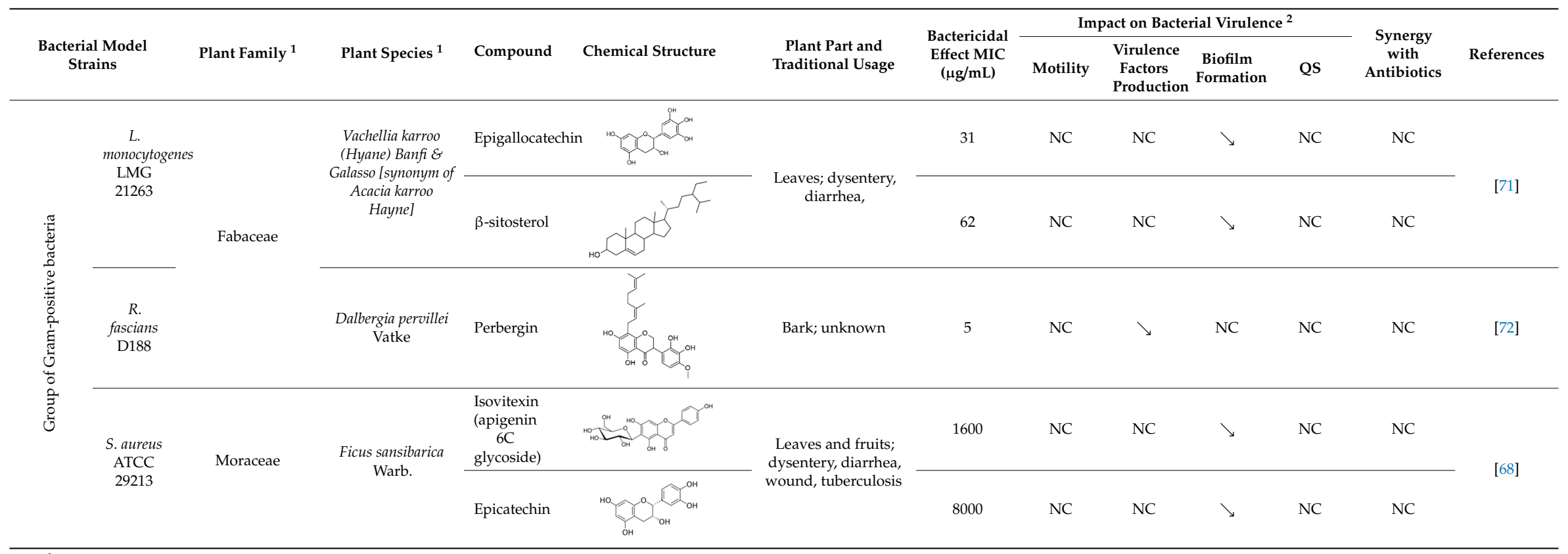

${ }^{1}$ All plant names and families were verified through the Medicinal Plant Names Services (MPNS) of Kew Royal Botanic Gardens (https://www.kew.org/science/our-science/science-
services/medicinal-plant-names-services) and, if not described in, MPNS through the Plant List portal (http://www.theplantlist.org/); ${ }^{2} \nearrow:$ Promotion; $\backslash$ : Inhibition; $\leftrightarrow:$ no impact; NC: not communicated. 


\subsection{Activities on Gram-Positive Bacteria}

Epicatechin $(8000 \mu \mathrm{g} / \mathrm{mL}, 3.4 \mathrm{mM})$ and isovitexin (apigenin 6-C-glucoside) $(200-500 \mu \mathrm{g} / \mathrm{mL}$ ) (0.4-1 mM) isolated from Ficus sansibarica Warb. subsp. Sansibarica, (Moraceae) collected in KwaZulu-Natal, South Africa, were found to decrease the adhesion of methicillin-susceptible S. aureus ATCC 29213, indicating the potential of flavonoids as antivirulence agents [68]. However, adhesion of methicillin-resistant S. aureus ATCC 43300 was increased in presence of isovitexin and the epicatechin isolated from the South African medicinal plant V. karroo does not inhibit biofilm formation by L. monocytogenes LMG 21263 [71], suggesting that inhibition of biofilm process by these compounds is strain-specific. Two other compounds (epigallocatechin and $\beta$-sitosterol), isolated from $V$. karroo, inhibit L. monocytogenes LMG 21263 biofilm formation at the concentration of $500 \mu \mathrm{g} / \mathrm{mL}(1.2 \mathrm{mM})$ [71]. Both present MICs at $31 \mu \mathrm{g} / \mathrm{mL}$ and $62 \mu \mathrm{g} / \mathrm{mL}(67$ and $149 \mu \mathrm{M})$, respectively. Considering these interesting bactericidal and antibiofilm properties, it is regrettable that no investigation on potential synergistic properties with conventional antibiotic has been performed so far; these could strengthen arguments to consider them as potential candidates for drug discovery and development.

Among Malagasy endemic Dalbergia species, D. pervillei Vatke (Fabaceae) exhibited attenuated gall phenotype when infected by the phytopathogen Rhodococcus fascians [72]. Further investigations led to the isolation of a prenylated isoflavanone, perbergin, which has been shown to target att $R$ gene expression, encoding a LysR-type transcriptional regulator that plays a key role in regulating the expression of virulence genes of $R$. fascians, notably its transition from an epiphytic to a pathogenic lifestyle [72]. Perbergin inhibited the induction of bacterial virulence att $R$ gene expression without any apparent loss of bacterial viability at $0.2 \mu \mathrm{M}$ but demonstrated strong bactericidal activity against R. fascians at $10 \mu \mathrm{M}$.

The monocyclic diterpenoid cassipourol and the phytosterol $\beta$-sitosterol, isolated from Platostoma rotundifolium (Briq.) A. J. Paton (Lamiaceae), a Burundian anti-infectious plant [75], inhibit QS-regulated and QS-regulatory genes expression in las and rhl systems and disrupt the formation of biofilms by P. aeruginosa at concentrations down to 12.5 and $50 \mu \mathrm{M}$, respectively [70]. Authors also isolated $\alpha$-amyrin, a biosynthesis precursor of ursolic acid [76], that exerts antibiofilm properties at $50 \mu \mathrm{M}$ without any effect on QS-regulatory genes expression; this suggests that other ursane and oleane-type triterpenes may exert antibiofilm properties with similar mechanisms of action. The three isolated compounds improve swimming but not twitching motilities which consequently promotes planktonic lifestyle in P. aeruginosa PAO1 and dispersal on preformed biofilms. Interestingly, the addition of cassipourol, $\alpha$-amyrin, and $\beta$-sitosterol $(100 \mu \mathrm{M})$ considerably improved the effectiveness of tobramycin $(50 \mu \mathrm{g} / \mathrm{mL}=107 \mu \mathrm{M})$ against $P$. aeruginosa PA01 with a drastic reduction in cell viability of biofilm-encapsulated bacteria $(89 \%, 70 \%$, and $76 \%$ of bacterial death, respectively, versus $40 \%$ in DMSO control treatment).

\section{Discussion}

African plants screened so far provide a clear indication that we have a fairly large source of non-microbicidal natural products active on bacteria (Tables 1 and 3). According to literature, the search for antivirulence activities have been shyly initiated since the last decade; by contrast, there has been a wide research on conventional antimicrobial activities (i.e., bactericidal activity) of African plants over the past 30 years [77-79]. Although African plants investigated for antivirulence activities are diverse (largely from Southern and Eastern African regions), very few studies have resulted in the characterization of the active compound(s), suggesting that this investigation is only beginning, which highlights a huge potential for new substances still to be discovered.

Considering that bacterial strategies to invade hosts may subtly differ according to species as well as within species, with different pathovars, it is difficult to claim that a single bacterial virulence target would be effective to undermine a bacterial invasion process. Although QS seems to be located at the crossroads of bacterial virulence expression, there is no universal QS system and cell-to-cell 
communication is differently exploited by bacterial species during bacterial infection, meaning that antivirulence compounds will generally be strain-specific.

Millennia of co-evolution between plants and pathogenic bacteria have led to complex defense strategies; invaded plants produce myriads of bactericidal and/or antipathogenic secondary metabolites that target different mechanisms. Although, the present African plants review highlights antivirulence properties, it is interesting to note that some of these plants also harbor bactericidal compounds with effects similar to those of conventional antibiotics. A relevant example is Platostoma rotundifolium in which compounds that exert bactericidal activities against S. aureus and E. coli (ursolic and corrosolic acid) coexist with compounds with antivirulence activities against $P$. aeruginosa (cassipourol, $\beta$-sitosterol, and $\alpha$-amyrin) $[70,80]$. Presumably, such a strategy allows plants to increase their probability of success in controlling bacterial invasions; this highlights that combined therapies, i.e., the use of two or multiple drugs with different antibacterial mechanisms of action, may represent an optimal strategy to sustainably struggle against bacterial infections, notably when a pathogen agent has not been specifically identified. In an empirical way, this type of strategy is adopted by tradipractices that often propose mixtures of medicinal plants to treat patients $[15,81]$. Thus, a combination of bactericidal agents and virulence inhibitors is expected to represent an effective therapeutic strategy to efficiently overcome bacterial infections. In this scenario, antivirulence agents would thwart the ability of bacteria to provoke severe infections or to evade immune defenses of the host, which conversely preserves or reinforces the bactericidal effectiveness of antibiotic agents; a rapid clearance of bacteria, including bacterial persister cells, by immune defenses would then be expected at each stage of invasion (Figure 2). Furthermore, in a synergistic approach, the efficiency of antibiotics could be achieved at lower concentrations, minimizing a selective pressure that is known to generate resistant bacteria spreading with collateral damages towards the commensal and symbiotic bacteria of the host.

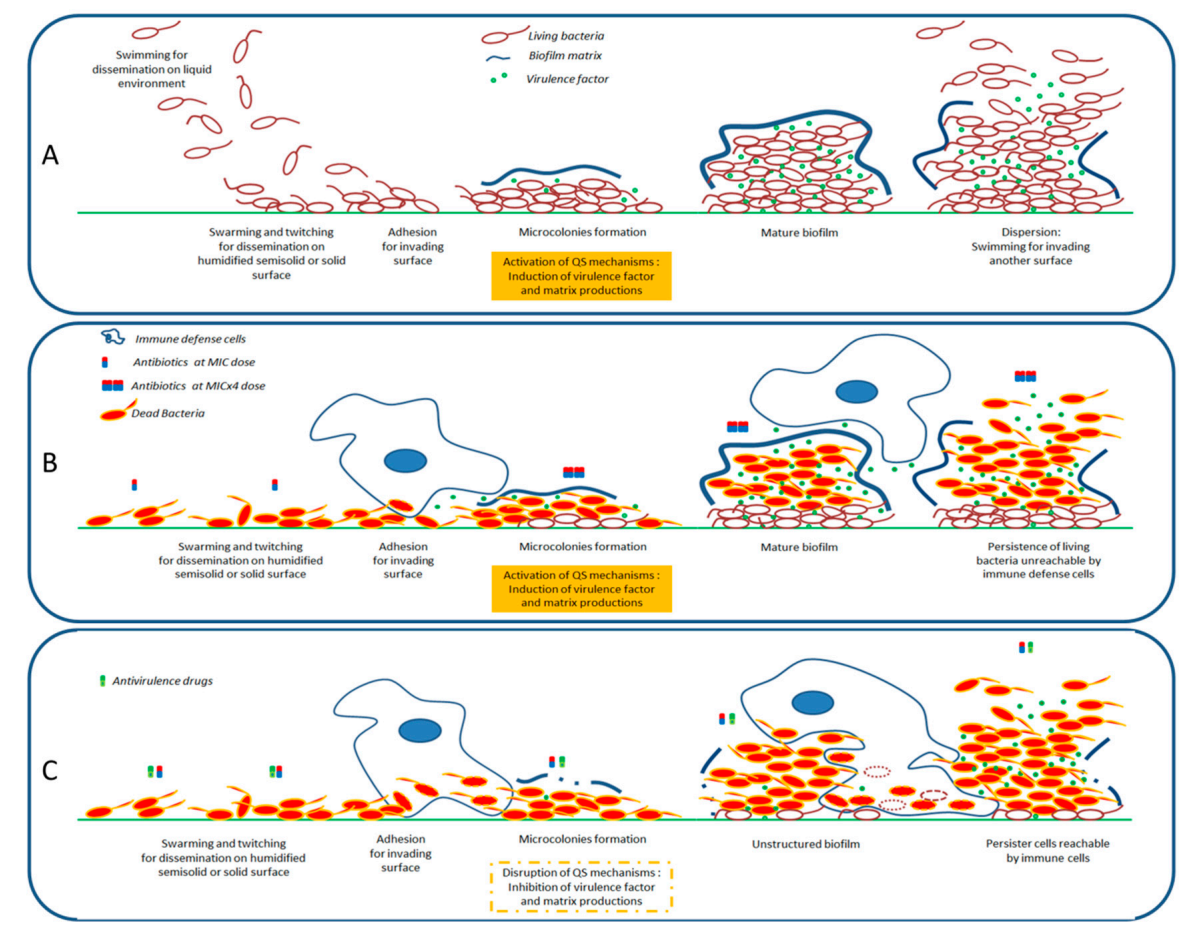

Figure 2. Model of antibiotherapy combined with an antivirulence agent. (A) Schematic representation of bacterial invasion processes. (B) Scenario presenting the use of antibiotherapy alone and the difficulty of immune defense cells to clear biofilm-encapsulated bacteria even at high doses of antibiotic (e.g., four to 100-fold MICs [82,83]). (C) Scenario presenting the simultaneous use of antibiotic and antivirulence agents; antibiotics at MICs kill a majority of bacteria gathered inside an unstructured biofilm which can be easily cleared by immune defense cells. 
So far, however, it should be acknowledged that the discovery of QS modulators has not yet led to major therapeutic breakthroughs; also, QS systems do not control the totality of virulence factors expression and the development of anti-QS bacterial resistance cannot be excluded [84]. However, this should not prevent further research in this promising field. Indeed, according to in vitro experiments, the combination of antibiotics and antivirulence (e.g., cassipourol) agents has already demonstrated its potential and about 33 compounds or agents, mainly from synthetic origin, that target virulence factors are under way for preclinical investigations, most of them focusing on P. aeruginosa, Enterobacteriaceae spp., and S. aureus [85-87].

Supplementary Materials: The following are available online at http:/www.mdpi.com/2079-6382/9/11/0830/ s1, Text S1: The QS circuitries of Pseudomonas aeruginosa, Staphylococcus aureus, Escherichia coli, and Ralstonia solanacearum.

Author Contributions: Conceptualization, M.E. and T.R.; Methodology, M.E. and T.R.; Investigation, C.E.M. and T.R.; Resources, C.E.M. and T.R.; Data curation, C.E.M. and T.R.; Writing-original draft preparation, T.R.; Writing-review and editing, P.D., M.E., and T.R. All authors have read and agreed to the published version of the manuscript.

Funding: This research received no external funding.

Acknowledgments: The authors would like to thank ARES (Académie de Recherche et d'Enseignement Supérieur, Belgium) for financial support throughout PRD projects and Doctoral Fellowship.

Conflicts of Interest: The authors declare no conflict of interest. The funders had no role in the design of the study; in the collection, analyses, or interpretation of data; in the writing of the manuscript, or in the decision to publish the results.

$\begin{array}{ll}\text { Abbreviation } \\ \text { AHL } & \text { acyl homoserine lactone } \\ \text { AI } & \text { autoinducer } \\ \text { EPS } & \text { exopolysaccharide polymers } \\ \text { ETEC } & \text { enterotoxigenic } E \text {. coli } \\ \text { HSL } & \text { homoserine lactone } \\ \text { MIC } & \text { minimal inhibition concentration } \\ \text { QQ } & \text { quorum quenching } \\ \text { QS } & \text { quorum sensing }\end{array}$

\section{References}

1. WHO. World Health Organization Releases GLOBAL priority List of Antibiotic-Resistant Bacteria to Guide Research, Discovery, and Development of New Antibiotics. J. Med. Soc. 2017, 32, 76-77.

2. Álvarez-Martínez, F.J.; Barrajón-Catalán, E.; Micol, V. Tackling Antibiotic Resistance with Compounds of Natural Origin: A Comprehensive Review. Biomedicines 2020, 8, 405. [CrossRef] [PubMed]

3. Andersson, D.I.; Hughes, D. Antibiotic Resistance and Its Cost: Is It Possible to Reverse Resistance? Nat. Rev. Microbiol. 2010, 8, 260-271. [CrossRef] [PubMed]

4. Spellberg, B.; Talbot, G. Recommended Design Features of Future Clinical Trials of Antibacterial Agents for Hospital-Acquired Bacterial Pneumonia and Ventilator-Associated Bacterial Pneumonia. Clin. Infect. Dis. 2010, 51, 150-170. [CrossRef] [PubMed]

5. Rasamiravaka, T.; Vandeputte, O.M.; Pottier, L.; Huet, J.; Rabemanantsoa, C.; Kiendrebeogo, M.; Andriantsimavandy, A.; Rasamindrakotroka, A.; Stévigny, C.; Duez, P.; et al. Pseudomonas aeruginosa Biofilm Formation and Persistence, along with the Production of Quorum Sensing-Dependent Virulence Factors, Are Disrupted by a Triterpenoid Coumarate Ester Isolated from Dalbergia trichocarpa, a Tropical Legume. PLoS ONE 2015, 10, e0132791. [CrossRef] [PubMed]

6. Carette, J.; Nachtergael, A.; Duez, P.; El Jaziri, M.; Rasamiravaka, T. Natural Compounds Inhibiting Pseudomonas aeruginosa Biofilm Formation by Targeting Quorum Sensing Circuitry. In Bacterial Biofilms; Intechopen: London, UK, 2020.

7. Dickey, S.W.; Cheung, G.Y.C.; Otto, M. Different Drugs for Bad Bugs: Antivirulence Strategies in the Age of Antibiotic Resistance. Nat. Rev. Drug Discov. 2017, 16, 457-471. [CrossRef] [PubMed] 
8. Ogawara, H. Possible Drugs for the Treatment of Bacterial Infections in the Future: Anti-Virulence Drugs. J. Antibiot. 2020, 1-18. [CrossRef]

9. Mion, S.; Rémy, B.; Plener, L.; Chabrière, É.; Daudé, D. Quorum Sensing and Quorum Quenching: How to Disrupt Bacterial Communication to Inhibit Virulence? Med. Sci. 2019, 35, 31-38.

10. Manach, C.; Scalbert, A.; Morand, C.; Rémésy, C.; Jiménez, L. Polyphenols: Food Sources and Bioavailability. Am. J. Clin. Nutr. 2004, 79, 727-747. [CrossRef]

11. Song, X.; Xia, Y.X.; He, Z.D.; Zhang, H.J. A Review of Natural Product with Anti-Biofilm Activity. Curr. Org. Chem. 2018, 22, 789-817. [CrossRef]

12. Jakobsen, T.H.; van Gennip, M.; Phipps, R.K. Ajoene, a Sulfur-Rich Molecule from Garlic, Inhibits Genes Controlled by Quorum Sensing. Antimicrob. Agents Chemother. 2012, 56, 2314-2325. [CrossRef] [PubMed]

13. Luo, J.; Dong, B.; Wang, K.; Cai, S.; Liu, T.; Cheng, X.; Chen, Y. Baicalin Inhibits Biofilm Formation, Attenuates the Quorum Sensing-Controlled Virulence and Enhances Pseudomonas aeruginosa Clearance in a Mouse Peritoneal Implant Infection Model. PLoS ONE 2017, 12, e0176883. [CrossRef]

14. Mahomoodally, M.F. Traditional Medicines in Africa: An Appraisal of Ten Potent African Medicinal Plants. Evid. Based Complement. Altern. Med. 2013, 2013, 1-14. [CrossRef] [PubMed]

15. Kahumba, J.; Rasamiravaka, T.; Okusa, P.N.; Bakari, A.S.; Bizumukama, L.; Kiendrebeogo, M.; El Jaziri, M.; Williamson, E.M.; Duez, P. Traditional African Medicine: From Ancestral Know-How to Bright Future. Science 2015, 350, S61-S63.

16. Ehrman, T.M.; Barlow, D.J.; Hylands, P.J. Phytochemical Databases of Chinese Herbal Constituents and Bioactive Plant Compounds with Known Target Specificities. J. Chem. Inf. Model. 2007, 47, 254-263. [CrossRef] [PubMed]

17. Wu, H.J.; Wang, A.H.J.; Jennings, M.P. Discovery of Virulence Factors of Pathogenic Bacteria. Curr. Opin. Chem. Biol. 2008, 12, 93-101. [CrossRef]

18. Rutherford, S.T.; Bassler, B.L. Bacterial Quorum Sensing: Its Role in Virulence and Possibilities for Its Control. Cold Spring Harb. Perspect. Med. 2012, 2, a012427. [CrossRef]

19. Pollitt, E.J.G.; Diggle, S.P. Defining Motility in the Staphylococci. Cell. Mol. Life Sci. 2017, 74, $2943-2958$. [CrossRef]

20. Sharma, A.K.; Dhasmana, N.; Dubey, N.; Kumar, N.; Gangwal, A.; Gupta, M.; Singh, Y. Bacterial Virulence Factors: Secreted for Survival. Indian J. Microbiol. 2017, 57, 1-10. [CrossRef]

21. Cress, B.F.; Englaender, J.A.; He, W.; Kasper, D.; Linhardt, R.J.; Koffas, M.A.G. Masquerading Microbial Pathogens: Capsular Polysaccharides Mimic Host-Tissue Molecules. FEMS Microbiol. Rev. 2014, 38, 660-697. [CrossRef]

22. Wang, H.; Zhong, Z.; Luo, Y.; Cox, E.; Devriendt, B. Heat-Stable Enterotoxins of Enterotoxigenic Escherichia coli and Their Impact on Host Immunity. Toxins 2019, 11, 24. [CrossRef] [PubMed]

23. Hall, S.; McDermott, C.; Anoopkumar-Dukie, S.; McFarland, A.J.; Forbes, A.; Perkins, A.V.; Davey, A.K.; Chess-Williams, R.; Kiefel, M.J.; Arora, D.; et al. Cellular Effects of Pyocyanin, a Secreted Virulence Factor of Pseudomonas aeruginosa. Toxins 2016, 8, 236. [CrossRef] [PubMed]

24. Kong, C.; Neoh, H.M.; Nathan, S. Targeting Staphylococcus aureus Toxins: A Potential Form of Anti-Virulence Therapy. Toxins 2016, 8, 72. [CrossRef] [PubMed]

25. Kristian, S.A.; Golda, T.; Ferracin, F.; Cramton, S.E.; Neumeister, B.; Peschel, A.; Götz, F.; Landmann, R. The Ability of Biofilm Formation Does Not Influence Virulence of Staphylococcus aureus and Host Response in a Mouse Tissue Cage Infection Model. Microb. Pathog. 2004, 36, 237-245. [CrossRef] [PubMed]

26. Archer, N.K.; Mazaitis, M.J.; Costerton, J.W.; Leid, J.G.; Powers, E.; Shirtliff, M.E. Staphylococcus aureus Biofilms Properties, Regulation and Roles in Human Disease. Virulence 2011, 2, 445-559. [CrossRef] [PubMed]

27. Beloin, C.; Roux, A.; Ghigo, J. Escherichia coli Biofilms. Curr. Top. Microbiol. Immunol. 2008, 322, $249-289$.

28. Rasamiravaka, T.; Labtani, Q.; Duez, P.; El Jaziri, M. The Formation of Biofilms by Pseudomonas aeruginosa: A Review of the Natural and Synthetic Compounds Interfering with Control Mechanisms. Biomed. Res. Int. 2015, 2015, 1-17. [CrossRef]

29. Franklin, M.J.; Nivens, D.E.; Weadge, J.T.; Lynne Howell, P. Biosynthesis of the Pseudomonas aeruginosa Extracellular Polysaccharides, Alginate, Pel, and Psl. Front. Microbiol. 2011, 2, 167. [CrossRef]

30. Tseng, B.S.; Zhang, W.; Harrison, J.J.; Quach, T.P.; Song, J.L.; Penterman, J.; Singh, P.K.; Chopp, D.L.; Packman, A.I.; Parsek, M.R. The Extracellular Matrix Protects Pseudomonas aeruginosa Biofilms by Limiting the Penetration of Tobramycin. Environ. Microbiol. 2013, 15, 2865-2878. 
31. Miyaue, S.; Suzuki, E.; Komiyama, Y.; Kondo, Y.; Morikawa, M.; Maeda, S. Bacterial Memory of Persisters: Bacterial Persister Cells Can Retain Their Phenotype for Days or Weeks after Withdrawal from Colony-Biofilm Culture. Front. Microbiol. 2018, 9, 1396. [CrossRef]

32. LaSarre, B.; Federle, M.J. Exploiting Quorum Sensing To Confuse Bacterial Pathogens. Microbiol. Mol. Biol. Rev. 2013, 77, 73-111. [CrossRef] [PubMed]

33. Mukherjee, S.; Moustafa, D.; Smith, C.D.; Goldberg, J.B.; Bassler, B.L. The RhlR Quorum-Sensing Receptor Controls Pseudomonas aeruginosa Pathogenesis and Biofilm Development Independently of Its Canonical Homoserine Lactone Autoinducer. PLoS Pathog. 2017, 13, e1006504. [CrossRef] [PubMed]

34. Naik, M.M.; Bhangui, P.; Bhat, C. The First Report on Listeria monocytogenes Producing Siderophores and Responds Positively to N-Acyl Homoserine Lactone (AHL) Molecules by Enhanced Biofilm Formation. Arch. Microbiol. 2017, 199, 1409-1415. [CrossRef] [PubMed]

35. Pandit, S.; Sarode, S.; Chandrasekhar, K. Fundemantals of Bacterial Biofilm: Present State of Art; Springer Nature: Berlin, Germany, 2018; pp. 43-60.

36. Haudecoeur, E.; Faure, D. A Fine Control of Quorum-Sensing Communication in Agrobacterium tumefaciens. Commun. Integr. Biol. 2010, 3, 84-88. [CrossRef] [PubMed]

37. Jimenez, P.N.; Koch, G.; Thompson, J.A.; Xavier, K.B.; Cool, R.H.; Quax, W.J. The Multiple Signaling Systems Regulating Virulence in Pseudomonas aeruginosa. Microbiol. Mol. Biol. Rev. 2012, 76, 46-65. [CrossRef] [PubMed]

38. Bronner, S.; Monteil, H.; Prévost, G. Regulation of Virulence Determinants in Staphylococcus aureus: Complexity and Applications. FEMS Microbiol. Rev. 2004, 28, 183-200. [CrossRef]

39. Garmyn, D.; Gal, L.; Lemaitre, J.P.; Hartmann, A.; Piveteau, P. Communication and Autoinduction in the Species Listeria monocytogenes: A Central Role for the Agr System. Commun. Integr. Biol. 2009, 2, 371-374. [CrossRef]

40. Kim, C.S.; Gatsios, A.; Cuesta, S.; Lam, Y.C.; Wei, Z.; Chen, H.; Russell, M.R.; Shine, E.E.; Wang, R.; Wyche, T.P.; et al. Characterization of Autoinducer-3 Structure and Biosynthesis in E. coli. ACS Cent. Sci. 2020, 6, 197-206. [CrossRef]

41. Roussel, C.; Cordonnier, C.; Livrelli, V.; Van de Wiele, T.; Blanquet-Diot, S. Enterotoxigenic and Enterohemorrhagic Escherichia coli: Survival and Modulation of Virulence in the Human Gastrointestinal Tract. In Escherichia coli-Recent Advances on Physiology, Pathogenesis and Biotechnological Applications; Intechopen: London, UK, 2017; pp. 3-24.

42. Ujita, Y.; Sakata, M.; Yoshihara, A.; Hikichi, Y.; Kai, K. Signal Production and Response Specificity in the phc Quorum Sensing Systems of Ralstonia solanacearum Species Complex. ACS Chem. Biol. 2019, 14, 2243-2251. [CrossRef]

43. Chenia, H.Y. Anti-Quorum Sensing Potential of Crude Kigelia africana Fruit Extracts. Sensors 2013, 13, $2802-2817$. [CrossRef]

44. Baloyi, I.T.; Cosa, S.; Combrinck, S.; Leonard, C.M.; Viljoen, A.M. Anti-Quorum Sensing and Antimicrobial Activities of South African Medicinal Plants against Uropathogens. S. Afr. J. Bot. 2019, 122, 484-491. [CrossRef]

45. Bangré, Y.A.; Mètuor-dabiré, A.; Rouamba, A.; Kiendrebeogo, M.; Simporé, J. Antibacterial Activity of Methanol Bark Extract from Acacia dudgeoni craib. Ex Holl (Mimosaceae) on Growth of Cefotaxime Resistant Escherichia coli. Curr. Res. Microbiol. Biotechnol. 2018, 6, 1660-1664.

46. Ouedraogo, V.; Compaoré, E.; Rouamba, A.; Compaoré, M.; Kiendrebeogo, M. Anti-Virulence Activity of Three Medicinal Plants: Cassia occidentalis L., Crossopteryx febrifuga (Afzel Ex G. Don) Benth. and Zanthoxylum zanthoxyloides (Lam) Zep. and Timl. Int. J. Microbiol. Res. 2019, 29, 1-7. [CrossRef]

47. Ouedraogo, V.; Rouamba, A.; Compaore, M.; Sombié, P.A.E.D.; Kiendrebeogo, M. Acacia seyal Del Bark Extract Reduces Quorum Sensing-Controlled Virulence Factor Production and Biofilm Formation in Pseudomonas aeruginosa PAO1. Int. J. Curr. Res. Biosci. 2018, 5, 7-13. [CrossRef]

48. Ouedraogo, V.; Rouamba, A.; Compaoré, E.; Compaoré, M.; Kiendrebeogo, M. Antioxidant, AntiquorumSensing and Antibiofilm Activities of Balanites aegyptiaca (L.) Del. (Balanitaceae) and Terminalia macroptera Guill. and Perr. (Combretaceae). Adv. Biochem. 2018, 6, 26-31. [CrossRef]

49. Bacha, K.; Tariku, Y.; Gebreyesus, F.; Zerihun, S.; Mohammed, A.; Weiland-Bräuer, N.; Schmitz, R.A.; Mulat, M. Antimicrobial and Anti-Quorum Sensing Activities of Selected Medicinal Plants of Ethiopia: Implication for Development of Potent Antimicrobial Agents. BMC Microbiol. 2016, 16, 139. [CrossRef] [PubMed] 
50. Famuyide, I.M.; Aro, A.O.; Fasina, F.O.; Eloff, J.N.; McGaw, L.J. Antibacterial and Antibiofilm Activity of Acetone Leaf Extracts of Nine Under-Investigated South African Eugenia and Syzygium (Myrtaceae) Species and Their Selectivity Indices. BMC Complement. Altern. Med. 2019, 19, 141. [CrossRef]

51. Omwenga, E.O.; Hensel, A.; Pereira, S.; Shitandi, A.A.; Goycoolea, F.M. Antiquorum Sensing, Antibiofilm Formation and Cytotoxicity Activity of Commonly Used Medicinal Plants by Inhabitants of Borabu Sub-County, Nyamira County, Kenya. PLoS ONE 2017, 12, e0185722. [CrossRef]

52. Cosa, S.; Chenia, H. Investigating the Potential of Ten South African Indegenious Plants Extracts as Quorum Sensing Inhibitors (QSI) of Pseudomonas aeruginosa Virulence-Related Factors. J. Biotechnol. Biomater. 2014, 3,112 .

53. Sarkar, R.; Chaudhary, S.K.; Sharma, A.; Yadav, K.K.; Nema, N.K.; Sekhoacha, M.; Karmakar, S.; Braga, F.C.; Matsabisa, G.; Mukherjee, P.K.; et al. Anti-Biofilm Activity of Marula-A Study with the Standardized Bark Extract. J. Ethnopharmacol. 2014, 154, 170-175. [CrossRef]

54. Okusa, P.; Rasamiravaka, T.; Vandeputte, O.; Stvigny, C.; El Jaziri, M.; Duez, P. Extracts of Cordia gilletii De Wild (Boraginaceae) Quench the Quorum Sensing of Pseudomonas aeruginosa PAO1. J. Intercult. Ethnopharmacol. 2014, 3, 138. [CrossRef] [PubMed]

55. Rasamiravaka, T.; Raveloson, P.A.; Rajaonarivelo, P.J.; Rabemanantsoa, C.; Andrianarisoa, B.; Duez, P.; El Jaziri, M. Malagasy Traditional Treatments of Infectious Plant Diseases Exert Anti-Virulence Activities Against Pseudomonas aeruginosa and Ralstonia solanacearum. J. Microbiol. Biotechnol. Food Sci. 2018, 7, 377-382. [CrossRef]

56. Rasamiravaka, T.; Quentin, L.; Mol, A.; Megalizzi, V.; Rabemanantsoa, C.; Duez, P.; El Jaziri, M. An Active Fraction from Dalbergia trichocarpa Baker Disrupts the Formation and Maintenance of Biofilms in Pseudomonas aeruginosa PAO1. IARJSET 2016, 3, 124-133. [CrossRef]

57. Ouedraogo, V.; Kiendrebeogo, M. Methanol Extract from Anogeissus leiocarpus (DC) Guill. et Perr. (Combretaceae) Stem Bark Quenches the Quorum Sensing of Pseudomonas aeruginosa PAO1. Medicines 2016, 3, 26. [CrossRef]

58. Sandasi, M.; Leonard, C.M.; Viljoen, A.M. The In Vitro Antibiofilm Activity of Selected Culinary Herbs and Medicinal Plants against Listeria monocytogenes. Lett. Appl. Microbiol. 2010, 50, 30-35. [CrossRef]

59. Akhalwaya, S.; van Vuuren, S.; Patel, M. An In Vitro Investigation of Indigenous South African Medicinal Plants Used to Treat Oral Infections. J. Ethnopharmacol. 2018, 210, 359-371. [CrossRef]

60. Oosthuizen, C.B.; Gasa, N.; Hamilton, C.J.; Lall, N. Inhibition of Mycothione Disulphide Reductase and Mycobacterial Biofilm by Selected South African Plants. S. Afr. J. Bot. 2019, 120, 291-297. [CrossRef]

61. Ouedraogo, V.; Karama, I.; Rouamba, A.; Compaoré, M.; Kiendrebeogo, M. Acacia dudgeoni Craib. Ex Holl (Mimosaceae): Potential Inhibitor of Biofilm Formation and Quorum Sensing in P. aeruginosa PAO1. Int. J. Biotechnol. 2019, 23, 1-6. [CrossRef]

62. Sereme, A.; Millogo-Rasolodimby, J.; Guinko, S.; Nacro, M. Proprietes Therapeutiques des Plantes a Tanins Du Burkina Faso (Therapeutic Power of Tannins Producing Species of Burkina Faso). Afr. J. Tradit. Med. 2008, 15, 41-49.

63. Alawi, S.M.A.; Hossain, M.A.; Abusham, A.A. Antimicrobial and Cytotoxic Comparative Study of Different Extracts of Omani and Sudanese Gum acacia. J. Basic Appl. Sci. 2018, 7, 22-26. [CrossRef]

64. Rasamiravaka, T.; Jedrzejowski, A.; Kiendrebeogo, M.; Rajaonson, S.; Randriamampionona, D.; Rabemanantsoa, C.; Andriantsimavandy, A.; Rasamindrakotroka, A.; Duez, P.; El Jaziri, M.; et al. Endemic Malagasy Dalbergia species Inhibit Quorum Sensing in Pseudomonas aeruginosa PAO1. Microbiology 2013, 159, 924-938. [CrossRef]

65. Rasamiravaka, T.; Rajaonarivelo, J.P.; Rabemanantsoa, C.; El Jaziri, M.; Andrianarisoa, B.; Duez, P. Malagasy Traditional Treatments for Food Crops: A Tool to Control Potato Bacterial Diseases? Crop. Prot. 2017, 102, 49-55. [CrossRef]

66. Okusa, P.N.; Penge, O.; Devleeschouwer, M.; Duez, P. Direct and Indirect Antimicrobial Effects and Antioxidant Activity of Cordia gilletii De Wild (Boraginaceae). J. Ethnopharmacol. 2007, 112, 476-481. [CrossRef]

67. Awolola, G.V.; Koorbanally, N.A.; Chenia, H.; Shode, F.O.; Baijnath, H. Antibacterial and Anti-Biofilm Activity of Flavonoids and Triterpenes Isolated. Afr. J. Tradit. Complement. Altern. Med. 2014, 3, 124-131. [CrossRef] 
68. Vandeputte, O.M.; Kiendrebeogo, M.; Rajaonson, S.; Diallo, B.; Mol, A.; El Jaziri, M.; Baucher, M. Identification of Catechin as One of the Flavonoids from Combretum albiflorum Bark Extract That Reduces the Production of Quorum-Sensing-Controlled Virulence Factors in Pseudomonas aeruginosa PAO1. Appl. Environ. Microbiol. 2010, 76, 243-253. [CrossRef]

69. Ouedraogo, V.; Sombié, P.A.E.; Compaoré, M.; Kiendrébéogo, M. Anti-Quorum Quenching Activity of Methyl Gallate Isolated from Galls of Guiera senegalensis J. F. Gmel (Combretaceae). Afr. J. Microbiol. Res. 2019, 13, 290-297.

70. Rasamiravaka, T.; Ngezahayo, J.; Pottier, L.; Ribeiro, S.O.; Souard, F.; Hari, L.; Stévigny, C.; El Jaziri, M.; Duez, P. Terpenoids from Platostoma rotundifolium (Briq.) A. J. Paton Alter the Expression of Quorum Sensing-Related Virulence Factors and the Formation of Biofilm in Pseudomonas aeruginosa PAO1. Int. J. Mol. Sci. 2017, 18, 1270. [CrossRef]

71. Nyila, M.A.; Leonard, C.M.; Hussein, A.A.; Lall, N. Activity of South African Medicinal Plants against Listeria monocytogenes Biofilms, and Isolation of Active Compounds from Acacia karroo. S. Afr. J. Bot. 2012, 78, 220-227. [CrossRef]

72. Rajaonson, S.; Vandeputte, O.M.; Vereecke, D.; Kiendrebeogo, M.; Ralambofetra, E.; Stévigny, C.; Duez, P.; Rabemanantsoa, C.; Mol, A.; Diallo, B.; et al. Virulence Quenching with a Prenylated Isoflavanone Renders the Malagasy Legume Dalbergia pervillei Resistant to Rhodococcus fascians. Environ. Microbiol. 2011, 13, 1236-1252. [CrossRef]

73. Jongkind, C.C.H. Prodromus for a Revision of Combretum (Combretaceae) for Madagascar. Bull. Mus. Natl. Hist. Nat. 1995, 17, 191-200.

74. Hossain, M.A.; Lee, S.J.; Park, N.H.; Mechesso, A.F.; Birhanu, B.T.; Kang, J.; Reza, M.A.; Suh, J.W.; Park, S.C. Impact of Phenolic Compounds in the Acyl Homoserine Lactone-Mediated Quorum Sensing Regulatory Pathways. Sci. Rep. 2017, 7, 1-16. [CrossRef] [PubMed]

75. Ngezahayo, J.; Havyarimana, F.; Hari, L.; Stévigny, C.; Duez, P. Medicinal Plants Used by Burundian Traditional Healers for the Treatment of Microbial Diseases. J. Ethnopharmacol. 2015, 173, 338-351. [CrossRef] [PubMed]

76. Babalola, I.T.; Shode, F.O. Ubiquitous Ursolic Acid: A Potential Pentacyclic Triterpene Natural Product. J. Pharmacogn. Phytochem. 2013, 2, 214-222.

77. Khameneh, B.; Iranshahy, M.; Soheili, V.; Fazly Bazzaz, B.S. Review on Plant Antimicrobials: A Mechanistic Viewpoint. Antimicrob. Resist. Infect. Control 2019, 8, 2-28. [CrossRef]

78. Madureira, A.M.; Ramalhete, C.; Mulhovo, S.; Duarte, A.; Ferreira, M.J.U. Antibacterial Activity of Some African Medicinal Plants Used Traditionally Against Infectious Diseases. Pharm. Biol. 2012, 50, 481-489. [CrossRef]

79. Van Vuuren, S.F. Antimicrobial Activity of South African Medicinal Plants. J. Ethnopharmacol. 2008, 119, 462-472. [CrossRef]

80. Ngezahayo, J.; Pottier, L.; Ribeiro, S.O.; Delporte, C.; Fontaine, V.; Hari, L.; Stévigny, C.; Duez, P. Plastotoma rotundifolium Aerial Tissue Extract Has Antibacterial Activities. Ind. Crops Prod. 2016, 86, 301-310. [CrossRef]

81. Xu, Q.; Bauer, R.; Hendry, B.M.; Fan, T.P.; Zhao, Z.; Duez, P.; Simmonds, M.S.J.; Witt, C.M.; Lu, A.; Robinson, N.; et al. The Quest for Modernisation of Traditional Chinese Medicine. BMC Complement. Altern. Med. 2013, 13, 132-143. [CrossRef]

82. Ceri, H.; Olson, M.E.; Stremick, C.; Read, R.R.; Morck, D.; Buret, A. The Calgary Biofilm Device: New Technology for Rapid Determination of Antibiotic Susceptibilities of Bacterial Biofilms. J. Clin. Microbiol. 1999, 37, 1771-1776. [CrossRef]

83. Strugeon, E.; Tilloy, V.; Ploy, M.-C.; Da Re, S. The Stringent Response Promotes Antibiotic Resistance Dissemination by Regulating Integron Integrase Expression in Biofilms. mBio 2016, 7, 1-9. [CrossRef]

84. Mellbye, B.; Schuster, M. The Sociomicrobiology of Antivirulence Drug Resistance: A Proof of Concept. mBio 2011, 2, 1-4. [CrossRef] [PubMed]

85. Parrino, B.; Schillaci, D.; Carnevale, I.; Giovannetti, E.; Diana, P.; Cirrincione, G.; Cascioferro, S. Synthetic Small Molecules as Anti-Biofilm Agents in the Struggle against Antibiotic Resistance. Eur. J. Med. Chem. 2019, 161, 154-178. [CrossRef]

86. Theuretzbacher, U.; Outterson, K.; Engel, A.; Karlén, A. The Global Preclinical Antibacterial Pipeline. Nat. Rev. Microbiol. 2020, 18, 275-285. [CrossRef] [PubMed] 
87. Rezzoagli, C.; Archetti, M.; Mignot, I.; Baumgartner, M.; Kümmerli, R. Combining Antibiotics with Antivirulence Compounds Can Have Synergistic Effects and Reverse Selection for Antibiotic Resistance in Pseudomonas aeruginosa. PLoS Biol. 2020, 18, e3000805. [CrossRef] [PubMed]

Publisher's Note: MDPI stays neutral with regard to jurisdictional claims in published maps and institutional affiliations.

(C) 2020 by the authors. Licensee MDPI, Basel, Switzerland. This article is an open access article distributed under the terms and conditions of the Creative Commons Attribution (CC BY) license (http://creativecommons.org/licenses/by/4.0/). 